\title{
Optimization of Fermentation Conditions for the Utilization of Brewing Waste to Develop a Nutraceutical Rich Liquid Product
}

\author{
Shilpi Gupta \\ Technological University Dublin, shilpi.19may@gmail.com \\ Amit Jaiswal \\ Technological University Dublin, amit.jaiswal@tudublin.ie \\ Nissreen Abu-Ghannam \\ Technological University Dublin, nissreen.abughannam@tudublin.ie
}

Follow this and additional works at: https://arrow.tudublin.ie/schfsehart

Part of the Food Biotechnology Commons, Food Chemistry Commons, Food Microbiology Commons, and the Food Processing Commons

\section{Recommended Citation}

Gupta, S., Jaiswal, A. K., \& Abu-Ghannam, N. (2013). Optimization of fermentation conditions for the utilization of brewing waste to develop a nutraceutical rich liquid product. Industrial Crops and Products, 44(0), 272-282. doi.org/10.1016/j.indcrop.2012.11.015

This Article is brought to you for free and open access by the School of Food Science and Environmental Health at ARROW@TU Dublin. It has been accepted for inclusion in Articles by an authorized administrator of ARROW@TU

Dublin. For more information, please contact arrow.admin@tudublin.ie, aisling.coyne@tudublin.ie, gerard.connolly@tudublin.ie.

Funder: Irish government under the Technological Sector Research Scheme (Strand III) of the National Development Plan

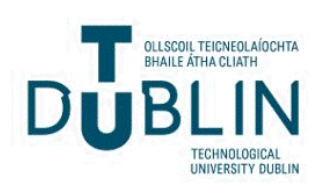


6

7

8

9

10

11

12

10

\section{Optimization of fermentation conditions for the utilization of brewing waste to develop}

\section{a nutraceutical rich liquid product}

Shilpi Gupta, Amit K. Jaiswal, Nissreen Abu-Ghannam

School of Food Science and Environmental Health,

College of Sciences and Health, Dublin Institute of Technology,

Cathal Brugha St., Dublin 1, Ireland.

\section{*Corresponding author: Dr. Nissreen Abu-Ghannam}

Tel: +353-1-402-7570; e mail: nissreen.abughannam@dit.ie 


\section{Abstract}

25

Utilization of brewers' spent grain (BSG), for the development of a fermented liquid product rich in value-added phenolic compounds was investigated. Changes in and liberation of phenolic compounds and antioxidant activity during fermentation of BSG was studied. The effect of various particle size (PS), solid liquid (SL) ratio, fermentation time and rotation speed was optimized using response surface methodology (RSM) for the purpose of improving bacterial growth and the enhancement in the release of polyphenolic compounds.

Contour maps generated using the response surface equation showed that the experimental variables significantly affected the response. A production of $10.4 \log \mathrm{cfu} / \mathrm{ml}, 2.95 \mathrm{~g} / 1$ lactic acid accompanied by a release of $268.6 \mathrm{mg}$ Gallic Acid Equivalent (GAE)/ml of phenolic compounds, $135 \mathrm{mg}$ Quercetin equivalent $(\mathrm{QE}) / \mathrm{ml}$ of flavonoid compounds, $33.7 \mathrm{mg} \mathrm{TE} / \mathrm{ml}$ ferric reducing antioxidant power (FRAP) and 75.1\% radical scavenging activity (RSA) was obtained with the optimized factors of $19 \mathrm{~h}$ fermentation time, $0.25 \mathrm{SL}$ ratio, $85 \mathrm{rpm}$ and $440 \mu \mathrm{m}$ PS. Shelf life was monitored over a period of 30 days and the product was shelf stable in terms of bioactive components for 15 days. The cell numbers, total phenol content and acidity (in terms of lactic acid) were maintained till 15 days storage period and a reduction was observed only after that.

Keywords: Brewers' spent grain, fermentation, antioxidant, heat processing, lactic acid, total phenol, nutraceuticals

\section{Introduction}

Agro-industrial by-product brewers' spent grain (BSG) is a low-value by-product of the brewing process consisting of the barley malt residue after mashing and lautering process. BSG is rich in cellulose (17\%) and non-cellulosic polysaccharides (mainly arabinoxylans) 
(39\%) (Valverde, 1994). The arabinose may be esterified with phenolic compounds such as hydroxycinnamic acid, monomeric or dimeric ferulic acid and p-coumaric acid (Bartolomé et al., 2002). The content of phenolic compounds in BSG may vary between $0.2-0.4 \%$. The large volume of BSG that is produced from the breweries is mainly utilized as animal feed or in landfills and its utilization for human consumption is relatively small. Because of its high moisture and fermentable sugar content, BSG becomes an environmental problem after a short time (7-10 days) (El-Shafey et al., 2004). There is an increasing pressure to ensure total utilisation of such by-products, so as to address economic and environmental concerns.

Due to the presence of polysaccharides and proteins, BSG has been used as a substitute to expensive carbon sources for industrial production of lactic acid. Production of $5.4 \mathrm{~g} / \mathrm{l}$ lactic acid was produced by Lactobacillus delbrueckii using BSG (Mussatto et al., 2007). Recently, interest in the addition of BSG as a means to enhance the quality of food products for human consumption has increased due to its richness in oligosaccharides and phenolic compounds. BSG has been incorporated as a source of dietary fibre in bread, cookies and ready-to-eat products (Ainsworth et al., 2007; Öztürk et al., 2002). However, reference searches indicate that studies on BSG utilization for the development of a functional fermented edible product have not been considered.

Overall performance of the fermentation by microorganisms can be affected by medium composition, presence of oxygen and product concentration. Furthermore, important parameters determining the release of nutrients from the solid substrate into the broth can be the ratio of the solids to liquid media and the particle size (PS) of the substrate. Maaroufi et al., (2000) reported that pea PS was found to have a strong influence on the chemical composition. The smaller the size of the particles, the higher the contents of crude protein and starch and the lower the content of crude fiber and water insoluble cell walls. Moreover, several literature reported work discuss the effects of PS and solid to solvent ratio on the 
release of phytochemicals such as phenolics and flavonoids with antioxidant activities during solvent extractions (Franco et al., 2007; Qu et al., 2010).

While optimizing a number of parameters to obtain high yields of the desired metabolic products, the 'one-at-a-time-approach' is not appropriate. Not only this method is extremely time consuming but also disregards the complex interactions among various physicochemical parameters (Abdel-Fattah et al., 2005). Response surface methodology (RSM) is a collection of mathematical and statistical techniques for searching optimum conditions of factors for desirable responses, and evaluating the relative significance of several affecting factors even in the presence of complex interactions. Box Behnken is a spherical, revolving RSM design that consists of a central point and the middle points of the edges of the cube circumscribed on the sphere. The design leads to the generation of contour plots by linear or quadratic effects of key variables and a model equation is derived that fits the experimental data to calculate the optimal response of the system.

This study aimed to utilize BSG for the purposes of development of a fermented liquid product rich in nutraceuticals. These objectives are justified having in mind that the literature lacks information on the fermentation of BSG for food applications. Therefore, a systematic approach was used to optimize the factors, which would facilitate the growth of lactic acid bacteria $(\mathrm{LAB})$ and the release of bioactive components in the broth. Thus, the effects of different SL ratio, rotation speed, PS of BSG and time of fermentation on the growth of LAB, lactic acid production, total phenolic content (TPC), total flavonoid content (TFC) and antioxidant values (in terms of DPPH-RSA and ferric reducing antioxidant power (FRAP)) for the development of a fermented liquid product were optimized by Box Behnken designs. Shelf life studies were also undertaken by evaluating the cell viability, lactic acid content, $\mathrm{pH}$ and phytochemical constituents. Finally, large scale production of the fermented edible 
product was carried out in a $7 \mathrm{~L}$ bioreactor under controlled conditions of $\mathrm{pH}$ and dissolved oxygen.

\section{Materials and Methods}

\subsection{Raw material and sample preparation}

BSG was obtained from a micro distillery plant located at University College Cork, Cork, Ireland and ground in a blender (Moulinex Opti Blend duo grinder). Particles were separated according to size using a sieve shaker (Model VS 1000, Retsch, Germany) with mesh size of $0.71,0.5,0.355$ and $0.18 \mathrm{~mm}$. Ground BSG was placed in the top sieve using the largest mesh and shaken for $5 \mathrm{~min}$ at an amplitude setting of $2 \mathrm{~mm}$, disassembled and stirred lightly, then shaken for additional $5 \mathrm{~min}$. The particles that passed from one sieve and were retained on the smaller sieve were then characterized into three different sizes and designated as $700 \mu \mathrm{m}$ (passing through $710 \mu \mathrm{m}$ and retained on $500 \mu \mathrm{m}$ ), $500 \mu \mathrm{m}$ (passing through $500 \mu \mathrm{m}$ but retained on $355 \mu \mathrm{m}$ ) and $350 \mu \mathrm{m}$ (passing through $355 \mu \mathrm{m}$ but retained on $180 \mu \mathrm{m}$ ). The sieve sizes were chosen based on the availability in the laboratory.

\subsection{Culture and Inoculum preparation}

Lactobacillus plantarum ATCC 8014 was purchased from Medical Supply Company, Dublin, Ireland. The culture was maintained at $-70^{\circ} \mathrm{C}$ in $20 \%$ glycerol stocks and grown in Man Rossa de Sharpe (MRS; (Scharlau Chemie, Barcelona, Spain)) broth at $37^{\circ} \mathrm{C}$. Sterile MRS broth $(25 \mathrm{ml})$ was inoculated with $1 \mathrm{ml}$ of thawed stock culture and incubated at $37^{\circ} \mathrm{C}$ for 12 $14 \mathrm{~h}$. This was then serially diluted 100 times to obtain working culture containing 6-7 log $\mathrm{cfu} / \mathrm{ml}$ cells as determined by plate counts.

\subsection{Preliminary study}


BSG taken for all the experiments was moistened with water in a ratio of 1:1. Moistened BSG (5 gm) was mixed with $50 \mathrm{ml}$ water and autoclaved at $121^{\circ} \mathrm{C}$ for $15 \mathrm{~min}$. The particle size (PS) and solid liquid (SL) ratio of $\mathrm{BSG}$ used was $355 \mu \mathrm{m}$ and 0.1 , respectively. The resulting single autoclaved (SA) broth was filtered through a cheese cloth to separate the BSG particles from the water. The filtrate $(50 \mathrm{ml})$ was dispensed in $250 \mathrm{ml}$ Erlenmeyer flasks and autoclaved again to obtain the double autoclaved (DA) broth which was inoculated with $5 \%$ inoculum and incubated at $37^{\circ} \mathrm{C}$. Samples were withdrawn at $0,12,24$ and $48 \mathrm{~h}$ and analyzed for $\log \mathrm{cfu} / \mathrm{ml}$, acid production and content of phytochemicals.

\subsection{Box-Behnken experimental design}

RSM was applied to investigate the influence of fermentation time $\left(\mathrm{X}_{1}\right)$, solid liquid (SL) ratio $\left(\mathrm{X}_{2}\right)$, speed of agitation $\left(\mathrm{X}_{3}\right)$ and particle size $\left((\mathrm{PS}), \mathrm{X}_{4}\right)$ on the growth of L. plantarum, acid production and the release of phytochemicals into the broth using Design Expert (Version 5.0.9) software (Stat-Ease Corporation, USA). In order to statistically optimize the medium components and evaluate main effects, interaction effects and quadratic effects of the four factors on various responses, a design with four factors and three levels including five replicates at the centre point was used. The non-linear computer-generated quadratic model is given as

$Y=\beta_{0}+\sum_{i=0}^{4} \beta_{i} X_{i}+\sum_{j=0}^{4} \beta_{i i} X_{i}^{2}+\sum_{i=0}^{4} \sum_{j=0}^{4} \beta_{i j} X_{i} X_{j}$

142 where $Y$ is the measured response associated with each factor level combination; $\beta_{0}$ is an intercept; $\beta_{i}$ is the regression coefficient computed from the observed experimental values of $144 Y$; and $X_{i}$ is the coded level of independent variables. The terms $X_{i}, X_{j}$ and $X_{i}^{2}$ represent the 145 interaction and quadratic terms, respectively. The independent variables selected are shown 146 in table 1 along with their low, medium, and high levels. 


\subsection{Fermentation of BSG}

To prepare the BSG fermented drinkable product for RSM studies, $5 \mathrm{~g} \mathrm{BSG}$ of the required PS was mixed with water as per the nutrient illustration (table 2) in order to achieve the required SL ratio. This was then autoclaved at $121^{\circ} \mathrm{C}$ for $15 \mathrm{~min}$. After cooling, the resulting SA broth was filtered through a cheese cloth to separate the BSG particles from the water. The filtrate $(50 \mathrm{ml})$ was dispensed in $250 \mathrm{ml}$ Erlenmeyer flasks and autoclaved again to obtain the double autoclaved (DA) broth. The DA broth was cooled to room temperature and inoculated with $5 \%$ inoculum. The flasks were then incubated at the required agitation as given in table 2. Two flasks of fermented product were withdrawn for sampling as per the time given by the software designed experiments (table 2). The samples were analyzed for $\mathrm{pH}$, viable cell count, lactic acid, TPC, TFC, FRAP and DPPH.

\subsection{Optimization of the factors}

After fitting the models and residual analysis of all responses, the multiresponse analysis of response surface design using desirability approach (Xiao et al., 2006) was used to optimize the four factors for achieving the maximal response. The general approach is to first convert each response into an individual desirability function $d_{i}$ that varies for the range $0 \leq d_{i} \leq 1$, where if the response is at its goal or target then, $d_{i}=1$, and if the response is outside acceptable region then $d_{i}=0$. The desired goal was selected by adjusting the weight or importance that might alter the characteristics of a goal. The goal fields for response have five options: none, maximum, minimum, target and within range. For each goal, the importance can be varied from 1 (less importance) to 5 (maximum importance). As the aim was to achieve higher concentration of all the responses the goal was set to 'maximize' with importance ' 5 '. Then the design variables are chosen to maximize the overall desirability: 
$171 \quad D=\left(d_{1} \times d_{2} \times d_{3} \times \ldots \ldots d_{n}\right)^{\frac{1}{n}}$

172 Where $n$ is number of responses.

\subsection{Shelf life evaluation}

The optimized values of the different factors were then selected to carry out shelf life analysis of the fermented product. Fermentation under optimized conditions were carried out in 100 $\mathrm{ml}$ Erlenmeyer flasks containing $50 \mathrm{ml}$ product for $19 \mathrm{~h}$ which was then refrigerated at $4^{\circ} \mathrm{C}$. Two flasks of the fermented product were withdrawn for sampling at regular intervals of 3-4 days for 30 days and analyzed for $\mathrm{pH}$, lactic acid, viable cell count and phtyochemical content.

\subsection{Kinetics under controlled $\mathrm{pH}$}

Seed culture $(200 \mathrm{ml})$ was prepared as mentioned in section 2.2. Cultivation was carried out at $37^{\circ} \mathrm{C}$ in a $7 \mathrm{~L}$ Bioflo 415 (New Brunswick, Mason Technology, Dublin, Ireland) bioreactor containing $4 \mathrm{~L}$ of SA broth. The reactor containing the SA broth was sterilized in situ at $121^{\circ} \mathrm{C}$ for $20 \mathrm{~min}$, cooled and then inoculated with $5 \%$ inoculum (v/v). Culture $\mathrm{pH}$ was maintained at 7.0 by automatic addition of $2 \mathrm{~N} \mathrm{NaOH}$. Samples were withdrawn at 3-4 h interval and analyzed for $\log \mathrm{cfu} / \mathrm{ml}$, acid production, phytochemical content and antioxidant capacity.

\subsection{Analytical methods}

\subsubsection{Estimation of viable cell count, residual sugars and organic acids}

The $\mathrm{pH}$ of fermented BSG product was measured with a $\mathrm{pH}$ meter (Orion Model 520A, ATI-

Orion Research Inc, Boston, USA). Viable cell counts in the BSG broth (log cfu/ml) were 
determined by the standard plate method with MRS medium. The plates were incubated at $37^{\circ} \mathrm{C}$ for $36-48 \mathrm{~h}$ for cell enumeration.

Each sample of the fermented broth was centrifuged at $10,000 \mathrm{rpm}$ for $10 \mathrm{~min}$ at $4^{\circ} \mathrm{C}$. The supernatant was subjected to the analyses of organic acids and total sugar. Total sugars in the centrifuged broth were estimated by the phenol-sulphuric acid method (Dubois et al., 1956).

The cell-free broth was used for the determination of organic acids and sugars by HPLC. The system consisted of an HPLC column on an Alliance HPLC (Waters, e2695 Separation module) equipped with an auto sampler and controller with dual pump. The detection system consisted of a Waters $486 \mathrm{UV}$ detector $(210 \mathrm{~nm})$ and Waters 410 Differential refractometer (RI detector) connected in series. The data acquisition and integration were performed using the Empower software package. A $20 \mu \mathrm{l}$ of sample was injected into a thermostatically controlled compartment set at $65^{\circ} \mathrm{C}$ containing Rezex ROA- Organic acid $\mathrm{H}+(8 \%)(350 \times 7.8$ mm, Phenomenex, U.K.) column fitted with a guard column $(50 \times 7.8 \mathrm{~mm}$, Phenomenex, U.K.) at a flow rate of $0.6 \mathrm{ml} / \mathrm{min}$ using $0.005 \mathrm{M} \mathrm{H}_{2} \mathrm{SO}_{4}$ (Sigma-Aldrich, Germany) as the mobile phase. Each sample was injected two times. Standards for the organic acids (lactic, acetic, propionic, malic and citric), alcohols (ethanol and methanol) and sugars (glucose, xylose, mannose and arabinose) were used to identify and quantify the components in the samples.

\subsubsection{Phytochemical analysis}

2.9.2.1 Total phenolic content (TPC)

The TPC in the BSG liquid product was determined using Folin-Ciocalteau's phenol reagent (Taga et al., 1984). Absorbance of all the sample solutions against reagent blank was determined at $720 \mathrm{~nm}$ with a spectrophotometer (Genesys 20, Thermo Spectronic, WI, USA). The TPC was expressed as mg gallic acid equivalents (GAE)/ml. 


\subsubsection{HPLC-DAD analysis of polyphenolic compounds}

The HPLC system consisted of a reversed-phase HPLC column on an Alliance HPLC (Waters, e2695 Separations modules) equipped with an auto sampler and controller with dual pump, a 2998 photodiode array detector (PDA) and the Empower software. HPLC coupled with PDA was used for identification of the peaks. The PDA carried out recording of UV-vis spectrum of each peak of the chromatogram and thus allowed explicit attribution of each chromatographic peak to different class of polyphenols, since each class exhibits a characteristic UV-vis spectrum. An Atlantis C18 column $(250 \mathrm{~mm} \times 4.6 \mathrm{~mm}, 5 \mu \mathrm{m}$ particle size) from Waters (Waters, Milford, MA) was used for polyphenolic separation at $25^{\circ} \mathrm{C}$. Solvent system consisted of $6 \%$ acetic acid in $2 \mathrm{mM} / 1$ sodium acetate (Sigma-Aldrich, Germany) (Solvent A) and acetonitrile (Fischer Scientific, UK) (Solvent B) (Jaiswal et al., 2011). The system was run with a solvent gradient as follows: $0-15 \% \mathrm{~B}$ in $45 \mathrm{~min}, 15-30 \% \mathrm{~B}$ in $15 \mathrm{~min}, 30-50 \% \mathrm{~B}$ in $5 \mathrm{~min}$ and $50-100 \% \mathrm{~B}$ in $5 \mathrm{~min}$. A flow rate of $1 \mathrm{ml} / \mathrm{min}$ was used and total run time for samples was 70 min. Samples and mobile phases were filtered through a $0.22 \mu \mathrm{m}$ Millipore filter (Millipore, Bedford, MA) prior to HPLC injection and $20 \mu \mathrm{l}$ of sample was injected. The chromatograms were monitored at $280 \mathrm{~nm}$ (hydroxybenzoic acid) and $320 \mathrm{~nm}$ (hydroxycinnamic acids) and complete spectral data were recorded in the range of $220-600 \mathrm{~nm}$.

\subsubsection{Total flavonoid content (TFC)}

The TFC was determined by a colorimetric method described by Liu et al., (2009). TFC of the fermented broth was expressed as mg quercetin equivalents $(\mathrm{QE}) / \mathrm{ml}$.

\subsubsection{DPPH radical scavenging assay}


244 This assay was carried out as described in our earlier studies (Jaiswal et al., 2011). The ability 245 to scavenge the DPPH radical was calculated using the following equation:

246 Scavenging capacity $(\%)=\left[1-\left(\frac{A_{\text {sample }}-A_{\text {sample blank }}}{A_{\text {control }}}\right)\right] \times 100$

247 where, $A_{\text {control }}$ is the absorbance of the control (DPPH solution without sample), $A_{\text {sample }}$ is the 248 absorbance of the test sample (DPPH solution plus test sample) and $A_{\text {sample blank }}$ is the 249 absorbance of the sample only (sample without any DPPH solution).

\subsubsection{Ferric reducing antioxidant potential (FRAP) assay}

Total antioxidant power of the fermented broth was measured using FRAP assay according to the method reported in our earlier study (Jaiswal et al., 2011). Trolox (Sigma-Aldrich, Germany) was used as a standard and the results were expressed as mg trolox equivalents $(\mathrm{TE}) / \mathrm{ml}$.

\subsection{Statistical analysis}

All the experiments were carried out in triplicate and replicated at least twice. Results are expressed as average \pm standard deviation (SD). Data from the Box-Behnken factorial design were subjected to a second-order multiple regression analysis using least-squares regression to obtain the parameter estimated for the mathematical model. The regression analysis and analysis of variance (ANOVA) for Box-Behnken design were carried out using the Design Expert software. Analysis of variance (ANOVA) for other experiments was done using the STATGRAPHICS Centurion XV (StatPoint Technologies, Inc., Warrenton, VA). Values of $p$ $<0.05$ were considered as statistically significant.

\section{Results and Discussion}




\subsection{Preliminary studies}

269

Development of a new functional food demands several important factors to be considered; the most important of which are the bioactive components. In case of a fermented BSG based drinkable product, important parameters will be the content of phytochemicals (phenolic compounds and other compounds responsible for antioxidant activity) and the final viable cell population in addition to the amount of lactic acid being produced. Growth of $L$. plantarum in wheat and barley based media without the need of additional nutrients has been reported earlier (Patel et al., 2004). Studies are also available wherein industrial waste such as rice straw has been successfully fermented to lactic acid (Qi et al., 2007). However, no literature is available regarding the use of BSG for the development of a fermented drink. Hence, initial trials were carried out to find the applicability of BSG as a medium for the growth of L. plantarum. BSG was autoclaved with water in order to allow the release of nutrients in the broth. The resulting SA broth was a homogenous liquid media with nonfermentable BSG particles in suspension. The TPC and TFC in the SA broth was found to be 183.9 $\pm 3.1 \mathrm{mg} \mathrm{GAE} / \mathrm{ml}$ and $80 \pm 1.9 \mathrm{mg}$ QE/ml, respectively. The FRAP value in the SA broth was $24.3 \pm 0.4 \mathrm{mg} \mathrm{TE} / \mathrm{ml}$ whereas the RSA was $90.3 \%$ (34.2 $\pm 0.5 \mathrm{mg}$ AscE $/ \mathrm{ml})$. The total sugar content was $3.1 \pm 0.5 \mathrm{~g} / \mathrm{l}$. In addition, the presence of free xylose $(0.04 \mathrm{~g} / \mathrm{l})$, arabinose $(0.03 \mathrm{~g} / \mathrm{l})$ and glucose $(0.1 \mathrm{~g} / \mathrm{l})$ was also observed. This was encouraging as it was proved that heating does lead to release of nutrients and phytochemicals into the broth. However, the broth in the present state was not suitable for the development of a fermented drinkable product because of the presence of the BSG particles. Hence, a technique was developed wherein the SA broth was filtered through a cheese cloth and the filtrate was subjected to a second heat treatment $\left(121^{\circ} \mathrm{C}\right.$ for $\left.15 \mathrm{~min}\right)$. An increment of $5.2,1.7$ and $11.8 \%$ in TPC, TFC and FRAP values was seen in the DA broth as compared to the SA broth. There was no significant difference in the DPPH values $(\mathrm{P}>0.05)$. The increase could be due to the 
breakdown of complexes between the polysaccharides and phenolics which could have

294 broken due to an extra heat treatment.

295 Fermentation of the DA broth resulted in a generation of $9 \pm 0.08 \mathrm{log} \mathrm{cfu} / \mathrm{ml}$ with the 296 production of $1.8 \mathrm{~g} / 1$ lactic acid. The production of lactic acid resulted in a drop in the $\mathrm{pH}$ of 297 the media from $5.8 \pm 0.08$ to $3.6 \pm 0.02$. A maximum growth of L. plantarum of $10.11 \log _{10}$ $298 \mathrm{cfu} / \mathrm{ml}$ was reported for malt based media (Charalampopoulos et al., 2002) whereas 8.97-9.16

$\log _{10} \mathrm{cfu} / \mathrm{ml}$ were obtained with media of whole and white oat-based flour (Kedia et al., 2008). The growth of L. plantarum in BSG based media was comparable with these results. Production of $1.2 \mathrm{~g} / 1$ and $1.99 \mathrm{~g} / 1$ lactic acid has been reported upon fermentation of white flour (Kedia et al., 2008) and malt medium (Charalampopoulos et al., 2002) with $L$. plantarum. In another study, chemically pre-treated BSG was saccharified and used as a fermentation medium without nutrient supplementation for production of lactic acid by Lactobacillus delbrueckii which produced $5.4 \mathrm{~g} / 1$ lactic acid (Mussatto et al., 2007).

However, fermentation resulted in a slight reduction in the phytochemical content of the fermented product but the change was not significant. Earlier studies have reported that strictly controlled fermentation by some isolated strains of lactic bacteria resulted in no change in the antioxidant potency of final sauerkraut compared to fresh vegetable (Tolonen et al., 2004). Little or no change in the TPC for fermented cereals and tea as compared to the unfermented counterpart has been reported in other studies as well (Heong et al., 2011; Oyarekua, 2010). Nonetheless, the results obtained in this study were encouraging as there was a release of phytochemicals from the BSG particles into the broth and the content increased as a result of the process of double autoclaving. Furthermore, the phytochemical content was not destroyed upon fermentation. Besides, the present study utilized a simple hydrothermal processing as a means to break the complex lignocellulosic material to facilitate the release the sugars, antioxidants and phenolic compounds in contrast to acid-base 
hydrolysis method used in other studies involving non-food based application of BSG (Carvalheiro et al., 2004).

According to these preliminary trials, it was established that BSG which is generally discarded by the brewing industry could be fermented for the development of novel beverages. Thus, further work involved obtaining conditions which would result in maximal release of these phytochemicals in the broth in addition to supporting the growth of LAB.

\subsection{Optimization of parameters by Box-Behnken design}

Response Surface Methodology was used to establish the relationship between the variables with the obtained responses. The main factors selected for optimization were the PS of BSG, SL ratio, fermentation time and agitation. The 29 experiments proposed (table 2) by the BoxBehnken design with four factors and three levels including five replicates at the centre point were used for fitting a second-order response surface. The five centre point runs provided a measure of process stability and inherent variability. A comparison of predicted and experimental values for the effect of the four factors on the growth of L. plantarum, acid production and release of phytochemicals is shown in table 2. Analysis of these data allows construction of a 'sequential model sum of squares' summary table, 'lack of fit' table and 'model summary statistics' table for every response, indicating how terms of increasing complexity contribute to the total model. The software then analyzes each response separately and establishes a range of models (linear, quadratic, cubic) for each response. The model having a large F-value with $\mathrm{p}<0.05$, insignificant lack of fit and minimum predicted residual sum of squares (PRESS) is selected. Investigation of the associated probability revealed that for all the responses quadratic models resulted in the best fit. The cubic models were aliased, as expected, because the design matrix provided very few unique design points to determine all the terms in the cubic model. 


\subsubsection{Effect of process variables on cell growth and lactic acid production}

344 The model summary statistics showed the quadratic model to have the minimum PRESS 345 value and maximum predicted $\mathrm{R}^{2}$ value and thus was chosen for fitting the experimental data. 346 Experimental results for the growth of L. plantarum and acid production were fitted to a full 347 quadratic second order polynomial model by applying multiple regression analysis. The 348 equation obtained to predict the polynomial model for L. plantarum growth (equation 4) and 349 lactic acid production (equation 5) are as given below:

$350 \log c f u / m l=+7.07+0.15 X_{1}+7.25 X_{2}+0.00326 X_{3}+0.00468 X_{4}-0.0039 X_{1}^{2}-7.93 X_{2}^{2}-1.18 \mathrm{E}-$ $35105 X_{3}^{2}-3.83 \mathrm{E}-06 X_{4}^{2}-0.15 X_{1} X_{2}+1.19 \mathrm{E}-04 X_{1} X_{3}-2.94 \mathrm{E}-05 X_{1} X_{4}-0.013 X_{2} X_{3}+0.001 X_{2} X_{4}$ $352 \quad 3.07 \mathrm{E}-07 X_{3} X_{4}$

353 Lactic acid $=-0.96+0.088 X_{1}+1.03 X_{2}-0.0036 X_{3}+0.0024 X_{4}-0.002 X_{1}^{2}+6.36 \quad X_{2}^{2}+4.4 \mathrm{E}-$ $35406 X_{3}^{2}-2 \mathrm{E}-07 X_{4}^{2}+0.68 X_{1} X_{2}-6.5 \mathrm{E}-06 X_{1} X_{3}-9.3 \mathrm{E}-05 X_{1} X_{4}+0.014 X_{2} X_{3}-0.011 X_{2} X_{4}+3 \mathrm{E}-$ $35506 X_{3} X_{4}$

356 When the values of $X_{1}-X_{4}$ were substituted in the above equations, the predicted $\log \mathrm{cfu} / \mathrm{ml}$ 357 for L. plantarum and the corresponding concentration of lactic acid were obtained. In order to 358 determine the significance of the quadratic model, ANOVA analysis was conducted. The $P$ 359 values were used as a tool to check the significance of each coefficient, which also indicated 360 the interaction strength of each parameter. The smaller the $P$-values are, the bigger the 361 significance of the corresponding coefficient. Corresponding $P$-values (table 3 ) for $\log \mathrm{cfu} / \mathrm{ml}$ suggested that among the different factors, $X_{2}(\mathrm{SL}),\left(X_{1}\right)^{2}$ (time $\times$ time), $\left(X_{3}\right)^{2}$ (agitation $\times$ agitation) and $X_{2} \times X_{3}(\mathrm{SL} \times$ agitation $)$ were the significant model terms with a $P$-values less than 0.05. Therefore, they can act as limiting nutrients and a small variation in their concentrations will alter growth of $L$. plantarum to a considerable extent. The goodness of fit of the model was examined by $F$-test and the determination coefficient $R^{2}$. The greater the $F$ - 
value is from unity, the more certain it is that the factors explain adequately the variation in the data around its mean, and that the estimated factor effects are real. The analysis of variance showed that this regression model was highly significant $(P<0.01)$ as is evident from the Fisher, $F$-test ( $F_{\text {model }}$, the ratio of mean square regression to mean square residual is 5.43 ) and has a very low probability value $\left[\left(P_{\text {model }}>F\right)=0.0016\right]$. The value of 0.1851 for lack of 372 fit implies that it is not significant comparing to the pure error and that the model equation

was adequate for predicting L. plantarum growth. The fitness of the model was further confirmed by a satisfactory value of determination coefficient, which was calculated to be 0.8444 , indicating that $84.44 \%$ of the variability in the response could be predicted by the model. The low coefficient of variation $(\mathrm{CV}=1.17 \%)$ suggested that the model was precise and reliable.

For determination the interaction of factors on different responses, the contour plots were studied in detail for all possible combinations by keeping two parameters constant at a time. Figure 1a shows the effect of PS and fermentation time on $\log \mathrm{cfu} / \mathrm{ml}$. An increase in $\log$ $\mathrm{cfu} / \mathrm{ml}$ was seen with an increase in the fermentation time and PS up to $17 \mathrm{~h}$ and $580 \mu \mathrm{m}$, respectively. The response value decreased with a further increase in the PS or fermentation time. Similarly, contour plots (plots not shown) between time and agitation showed a positive effect of both these factors on log cfu/ml up to $16 \mathrm{~h}$ and $125 \mathrm{rpm}$, respectively. However, an increase in the SL ratio resulted in a continuous increase in $\log \mathrm{cfu} / \mathrm{ml}$ in contrast to PS wherein the response value increased only up to a PS of $570 \mu \mathrm{m}$.

P-values in case of lactic acid showed $X_{1}$ (time), $X_{2}$ (SL ratio), $X_{4}(\mathrm{PS}),\left(X_{1}\right)^{2}$ (time $\times$ time), $X_{1}$ $\times X_{2}($ time $\times \mathrm{SL})$ and $X_{2} \times X_{4}(\mathrm{SL} \times \mathrm{PS})$ to be significantly affecting the acid production having $\mathrm{P}<0.05$ (table 3 ). The analysis of variance showed that the regression model was significant $(P<0.01)$ with a Fisher, $F$-test value of 53.77 . The value of 0.0553 for lack of fit was insignificant and the model equation was adequate for predicting the production of lactic 
392

acid. The determination coefficient was calculated to be 0.9817 , indicating that $98.17 \%$ of the variability in the response could be predicted by the model.

Figure $1 \mathrm{~b}$ shows the contour plot between PS and agitation for lactic acid production. The contour clearly showed that PS and agitation were inversely affecting the response. An increase in agitation and a reduction in PS increased the value of the response. In contrast, contour between time and SL ratio showed an increase in the concentration of lactic acid as both the factors were continuously increased.

405 The predicted values for TPC can be obtained by substituting the values of $X_{1}-X_{4}$ in equation 406 6. Corresponding ANOVA analysis suggested that, $X_{2}(\mathrm{SL}), X_{4}(\mathrm{PS})$ and $\left(X_{2}\right)^{2}(\mathrm{SL} \times \mathrm{SL})$ are 407 significant model terms with $P<0.05$ and thus can act as limiting factors for TPC. The 408 regression model was found to be highly significant $(P<0.01)$ as is evident from the Fisher, $409 F$-test $\left(F_{\text {model }}\right.$, is 87.03 and has a very low probability value $\left[\left(P_{\text {model }}>F\right)<0.0001\right]$. The value 410 of 0.1022 for lack of fit implies that it is not significant comparing to the pure error and that 411 the model equation was adequate for predicting the TPC. The fitness of the model was further 412 confirmed by a satisfactory value of determination coefficient, which was calculated to be 4130.9886 , indicating that only $1.14 \%$ variability in the response could not be predicted by the 414 model. 
415 Figure 1c shows the two dimensional contour plot for the effect of agitation and time on the 416 TPC that was released in the broth. An increase in the agitation showed a reduction in the 417 TPC till $80 \mathrm{rpm}$ after which the value started increasing.

418 The quadratic model obtained for TFC was:

$419 T F C=-76.12+1.65 X_{1}+611.5 X_{2}-0.002 X_{3}+0.35 X_{4}-0.012 X_{1}^{2}-1002.7 X_{2}^{2}-3.2 \mathrm{E}-04 X_{3}^{2}-2.9 \mathrm{E}-$

421 Corresponding ANOVA analysis suggested $X_{2}(\mathrm{SL}),\left(X_{2}\right)^{2}(\mathrm{SL} \times \mathrm{SL})$ and $\left(X_{4}\right)^{2}(\mathrm{PS} \times \mathrm{PS})$ to 422 be significant model terms with $P$-values of less than 0.05 . The regression model (Eq. 7) was 423 found to be highly significant $(P<0.01)$ with a value of 22.84 for $F_{\text {model }}$, a very low 424 probability value $\left[\left(P_{\text {model }}>F\right)<0.0001\right]$ and a non significant value of 0.2002 for lack of fit. 425 The determination coefficient was 0.9581 , indicating a good predictability of the model. 426 Figure 1d shows two-dimensional contour plot for the effect of agitation and PS on TFC. 427 Analyzing the contour showed that TFC content was increased up to a PS of $500 \mu \mathrm{m}$ with an 428 agitation of no more than $100 \mathrm{rpm}$. In a study on extraction of phenolic compounds from 429 grape byproducts, temperature and SL ratio were found to play the most critical role in 430 extraction efficiency (Pinelo et al., 2005). In another study, SL ratio was reported to be most 431 effective for enhancing the yield of total phenolics during extraction from black currants. The 432 content of phenolics increased with ethanol concentration up to a maximum at about $60 \%$ and 433 then decreased with further increase in solvent concentration irrespective of the SL ratio 434 (Cacace et al., 2003).

\subsubsection{Effect of process variables on DPPH and FRAP}

Table 2 shows the predicted and experimental values for DPPH and FRAP. For both the responses the regression model was found to be highly significant $(\mathrm{P}<0.01)$ with an 
439 insignificant lack of fit (0.8473 for FRAP and 0.3188 for DPPH). A high value of 440 determination coefficient (0.9759 for FRAP and 0.9360 for DPPH) indicated a good 441 predictability of the model. $X_{2}(\mathrm{SL}), X_{4}(\mathrm{PS}),\left(X_{2}\right)^{2}(\mathrm{SL} \times \mathrm{SL})$ and $\left(X_{4}\right)^{2}(\mathrm{PS} \times \mathrm{PS})$ were found 442 to be the significant model terms for FRAP and $X_{2}(\mathrm{SL}),\left(X_{2}\right)^{2}(\mathrm{SL} \times \mathrm{SL}), X_{1} \times X_{2}($ time $\times$ $443 \mathrm{SL}), X_{2} \times X_{4}(\mathrm{SL} \times \mathrm{PS})$ and $X_{3} \times X_{4}$ (agitation $\left.\times \mathrm{PS}\right)$ for DPPH (table 3$)$. The polynomial 444 equations for FRAP (Eq 8) and DPPH (Eq 9) are:

$445 F R A P=-12.05+0.7 X_{1}+204.28 X_{2}-0.012 X_{3}+0.056 X_{4}-0.0052 X_{1}^{2}-323.6 X_{2}^{2}+6.4 \mathrm{E}-05 X_{3}^{2}-$

$\mathrm{DPPH}=21.83+2.28 X_{1}+294.3 X_{2}-0.21 X_{3}-0.095 X_{4}-0.0029 X_{1}^{2}+937.7 X_{2}^{2}+9.91 \mathrm{E}-$ $05 X_{3}^{2}+1.5 \mathrm{E}-04 X_{4}^{2}-9.2 X_{1} X_{2}-2.2 \mathrm{E}-04 X_{1} X_{3}-0.002 X_{1} X_{4}-0.15 X_{2} X_{3}-0.38 X_{2} X_{4}+4.2 \mathrm{E}-$ $04 X_{3} X_{4}$

Figure 1e and 1f shows the two-dimensional contour plots for FRAP and DPPH, respectively. In both cases, an increase in the SL ratio resulted in an increase in the respective parameter. Examining the contour plot between time and PS further confirmed that time did not have an effect on the FRAP whereas a reduction in the FRAP values was observed after a PS of $500 \mu \mathrm{m}$. Increase in PS has been reported to result in a reduced yield and content of antioxidants from pomegranate marc (Qu et al., 2010).

\subsection{Multi response optimization}

The contour plots clearly showed the effect of different process variables on the responses.

Due to large number responses, the optimization was carried out by Numerical option of the Design expert software to achieve the best combination of input factors for obtaining maximal release of phytochemicals accompanied by a good growth of bacteria and acid 

475

production. In the numerical optimization, the desired goal for each factor and response was

464 selected. The desired goal was selected by adjusting the weight or importance that might alter 465 the characteristics of a goal. A weight can be assigned to each goal to adjust the shape of its 466 particular desirability function. The software then converts the goals into an overall 467 desirability function. Desirability function ranges from zero to one for the goals and the 468 program searches to maximize this function. Figure 2 shows a ramp desirability that was 469 generated from 10 optimum points via numerical optimization. The program randomly picks 470 a set of conditions from which it starts the search for desirable results. The ramp display 471 combines the individual graphs for easier interpretation. The dot on each ramp reflects the 472 factor setting or response prediction for that solution. The height of the dot shows how 473 desirable a particular response is. By seeking from 10 starting points in the response surface 474 changes, the best local maximum was found to be $10.4 \mathrm{log} \mathrm{cfu} / \mathrm{ml}, 268.6 \mathrm{mg} \mathrm{GAE} / \mathrm{ml} \mathrm{TPC}$, optimized factors of $19 \mathrm{~h}$ fermentation time, $0.25 \mathrm{SL}, 85 \mathrm{rpm}$ and $440 \mu \mathrm{m}$ PS. The individual desirability functions $\left(d_{i}\right)$ for each of the responses and the calculated geometric mean as maximum overall desirability $(D=0.882)$. Since it is difficult to obtain the exact PS of the BSG as given by the software, PS obtained in the range of $355-500 \mu \mathrm{m}$ (passing through $500 \mu \mathrm{m}$ but retained on $355 \mu \mathrm{m}$ ) was selected as the optimized one. Duplicate confirmatory experiments were conducted using the optimized parameters for validation. Experimental verification resulted in production of $10.33 \pm 0.12 \mathrm{log} \mathrm{cfu} / \mathrm{ml}$ and $2.5 \pm 0.22 \mathrm{~g} / \mathrm{l}$ lactic acid which were in close agreement with the predicted values. The values of TPC $(241.4 \pm 1.7 \mathrm{mg}$ GAE/ml), TFC (123.4 $\pm 4.7 \mathrm{mg}$ QE/ml), FRAP (31.64 $\pm 0.22 \mathrm{mg}$ TE/ml) and DPPH-RSA (69.1\%) were also closely related to the data obtained from optimization analysis although exact matching was not obtained due to a difference in the PS optimized by the software and 
that used for the experiment. However, the experiment affirms that the models developed could adequately predict the responses.

\subsection{HPLC-DAD analysis of the different broths and fermented product}

HPLC analysis of phenolics in the SA broth and DA broth obtained from the RSM optimized factors and fermented product was carried out to record the UV-vis spectrum. Explicit attribution of each chromatographic peak to distinct class of polyphenols was carried out on the basis of a characteristic UV-vis spectrum for each class. Two different groups of polyphenols were identified by comparing their UV-vis spectra with spectra of reference compounds and reported values (Abad-García et al., 2009). The hydroxybenzoic acid (HBA) derivatives (range $255-280 \mathrm{~nm}$ ) were quantified at $280 \mathrm{~nm}$ and expressed as gallic acid equivalents (GAE) and hydroxycinnamic acid (HCA) derivatives (range 310-325 nm) at $320 \mathrm{~nm}$ and expressed as chlorogenic acid equivalents (CAE). A distinctive HPLC chromatogram of the polyphenols released in the broth is shown in figure 3 . The chromatogram showed that the broth contained a mixture of more than 20 phenolics in SA broth and 21 phenolics in DA and fermented broth. Fourteen peaks were identified as HBA derivatives and six peaks as HCA derivatives in the case of SA broth. This number increased to 15 (HBA derivatives) and 5 (HCA derivatives) for DA broth. For fermented broth, 15 and 6 peaks were identified as HBA and HCA derivatives, respectively. The HPLC results (table 4) clearly replicated the values obtained in the TPC assay wherein an increase in the content of phenolic compounds was seen in the DA broth (as compared to the SA broth) which then reduced slightly upon fermentation. The difference in values of the spectrophtometric analysis and HPLC analysis could be due to the formation of free hydroxyl group(s) by linkage cleavages of polyphenol derivatives, for example, flavonoids, as compared to the 
quantitative content of hydroxybenzoic acid or hydroxycinnamic acids detected by HPLCDAD (Harbaum et al., 2008).

\subsection{Shelf life analysis}

The viable cell count at the end of the $19 \mathrm{~h}$ fermentation period was found to be $10.35 \log$ $\mathrm{cfu} / \mathrm{ml}$. The stability of $L$. plantarum during storage was monitored (figure 4 ) and a reduction of $1.34 \log \mathrm{cfu} / \mathrm{ml}$ was seen at the end of the 30 days storage period. The reduction was found to be significant $(\mathrm{P}<0.05)$. However, there was no significant difference in the log cfu/ml up to 15 days of storage period and the cell numbers started declining only after that. These results indicated that $L$. plantarum was capable of surviving for 15 days under high acidic conditions of BSG based fermented product during storage at $4^{\circ} \mathrm{C}$. High survival rates of $L$. plantarum in fermented products during storage under refrigerated conditions have been reported earlier (Gupta et al., 2010; Yoon et al., 2006). Mårtensson et al., (2002) reported high survival of Lactobacillus reuteri in oat based non-dairy products after 30 days of storage.

The lactic acid content remained constant up to day 8 after (figure 4) which a slight reduction of $4 \%$ was observed till day 15 . However, storage beyond 15 days resulted in a continuous reduction with the content significantly reducing $(\mathrm{P}<0.05)$ by $28 \%$ at the end of 30 days storage period. Results from the shelf life analysis showed that the $\mathrm{pH}$ on day 1 was 3.27 and remained almost constant up to 15 days. A slight increase in the $\mathrm{pH}$ value (figure 4) was seen after 18 days. However, single factor ANOVA analysis showed that the change in $\mathrm{pH}$ was not significant $(\mathrm{P}>0.05)$. Similar results were reported by Rozada et al., (2009) during the fermentation of a malt based beverage by Bifidobacterium breve.

The TPC and TFC value on day 1 was $220 \pm 2.3 \mathrm{mg} \mathrm{GAE} / \mathrm{ml}$ and $105.4 \pm 5.6 \mathrm{mg} \mathrm{QE} / \mathrm{ml}$, respectively. There was a slight reduction in the values after 15 days of storage which were 
536 further retained for the next 15 days storage period. No significant $(\mathrm{P}>0.05)$ change in the 537 antioxidant content was observed upon the 30 day storage period. HPLC analysis was also 538 carried out on the samples of day 15 and day 30 in order to analyze any change in the peak 539 areas for the phenolic compounds. The content of HBA and HCA had significantly reduced 540 after 15 days storage period. However, there was no significant difference $(\mathrm{P}>0.05)$ in the 541 HBA and HCA content in samples between 15 and 30 days storage.

\subsection{Fermentation in a 7-L bioreactor}

In order to study the growth kinetics on a large scale, a 7L lab scale BioFlo (New Brunswick, Mason Technology, Dublin, Ireland) bioreactor was used. Fermentation of BSG with a SL ratio of 0.25 and PS in the range of $355-500 \mu \mathrm{m}$ was carried out for $19 \mathrm{~h}$ at an agitation of $100 \mathrm{rpm}$ and under controlled conditions of $\mathrm{pH}$ (at 7). The content of TPC, TFC, DPPH and FRAP in the DA broth was $239.6 \pm 2.1 \mathrm{mg} \mathrm{GAE} / \mathrm{ml}, 120.8 \pm 2.9 \mathrm{mg}$ QE/ml, $30.98 \pm 1.1 \mathrm{mg}$ $\mathrm{TE} / \mathrm{ml}$ and $68.7 \% \mathrm{RSA}$, respectively. The change in cell growth and acid production as a result of the growth of L. plantarum can be seen in figure 5. The level of phytochemicals (TPC and TFC) and antioxidants (DPPH and FRAP) essentially remained unchanged during the course of fermentation. The lag phase was found to be even less than $2 \mathrm{~h}$ as evident from an increase of $0.6 \log \mathrm{cfu} / \mathrm{ml}$ after $2 \mathrm{~h}$ of fermentation. Occurrence of minimal lag phase has been reported in earlier studies on the growth of LAB in vegetable juice (Gupta et al., 2010; Kun et al., 2008) whereas Kedia et al., (2007) reported a lag phase of approximately 2 h upon the inoculation of $L$. reuteri cells into 5\% malt suspension. Cell concentration increased from $6.4 \pm 0.02 \log \mathrm{CFU} / \mathrm{ml}$ to $10.68 \pm 0.03 \log \mathrm{CFU} / \mathrm{ml}$ after $19 \mathrm{~h}$ of fermentation with a rate of production equivalent to $0.39 \mathrm{~h}^{-1}$. Such a cell growth led to the consumption of $2.1 \mathrm{~g} / 1$ total sugar. The viable cell numbers almost became constant as the stationary phase was achieved. The cell numbers obtained in the bioreactor were higher than those obtained when the 
561 cultivation was carried out in flasks. The reason for this could be the controlled $\mathrm{pH}$ in the 562 bioreactor which prevented the reduction in growth rate generally observed in flasks when 563 fermentation is carried out under uncontrolled $\mathrm{pH}$. Studies carried out under controlled $\mathrm{pH}$ 564 conditions have indicated that the accumulation of acids during the fermentation is 565 responsible for decrease in growth rate (Desjardins et al., 1990). Volumetric productivities of 566 L. plantarum was $2.5 \times 10^{12} \mathrm{cfu} / \mathrm{l}$ h. Nazzaro et al., (2008) reported the possibility of 567 producing a functional vegetal beverage based on the growth of Lactobacillus rhamnosus and 568 Lactobacillus bulgaricus in carrot juice with a growth of $5 \times 10^{9} \mathrm{cfu} / \mathrm{ml}$ in $48 \mathrm{~h}$, which 569 corresponds to a volumetric productivity of $1.04 \times 10^{11} \mathrm{cfu} / 1 \mathrm{~h}$. However, the results of the 570 present study are better as similar counts were obtained in shorter time resulting in higher 571 productivity.

572 The consumption of sugars during the exponential phase $(6-14 \mathrm{~h})$ resulted in the 573 accumulation of lactic acid $(2.7 \pm 0.7 \mathrm{~g} / 1)$ and acetic acid $(0.4 \pm 0.01 \mathrm{~g} / \mathrm{l})$. A homofermentative 574 metabolic pattern was observed for L. plantarum resulting in a production of mainly lactic 575 acid and small amounts of acetic acid. Peaks for other organic acids such as propionic, malic 576 or citric were not observed further confirming a homofermentative metabolic pathway. 577 Methanol and ethanol were not detected in the fermentation broth. The accumulation of lactic 578 acid continued during the stationary phase as well although the rate of accumulation had 579 drastically reduced. Once again the amount of lactic acid formed was higher than that 580 obtained for the values obtained in the flasks and can be attributed to the fermentation under 581 controlled $\mathrm{pH}$ conditions. However, due to the controlled $\mathrm{pH}$ conditions in the bioreactor the 582 product obtained was not acidic in nature and a difference in the aroma between the product 583 fermented in the bioreactor and that fermented in the flasks under uncontrolled $\mathrm{pH}$ conditions 584 was detected. 


\section{Conclusion}

587 Successful production of a fermented product from an industrial waste was carried out. Heat processing resulted in a release of bioactive compounds into the broth which were then retained upon the process of fermentation. The optimization of the different factors affecting the production of a functional drink established the appropriate solid liquid ratio, particle size, fermentation time and rate of agitation for completing a controlled fermentation. The finished product had high antioxidant capacity and could support the growth of LAB as well. The phytochemical content remained unchanged during the storage period. Shelf life of the fermented liquid product was estimated to be around 15 days under refrigerated conditions. Large-scale fermentation for the production of drink was also successfully carried out. The present study showed a good adaption of LAB in BSG based broth thus opening potentials 597 for the use of probiotic strains as a starter culture for a further improvement in the bioactive

\section{Acknowledgement}

The authors would like to acknowledge funding from the Irish government under the Technological Sector Research Scheme (Strand III) of the National Development Plan.

\section{References}

Abad-García, B., Berrueta. L.A., Garmón-Lobato, S., Gallo, B., Vicente, F., 2009. A general analytical strategy for the characterization of phenolic compounds in fruit juices by highperformance liquid chromatography with diode array detection coupled to electrospray ionization and triple quadrupole mass spectrometry. J. Chromat. A 1216, 5398-5415. 
610 Abdel-Fattah, Y.R., Saeed, H.M., Gohar, Y.M., El-Baz, M.A., 2005. Improved production of 611 Pseudomonas aeruginosa uricase by optimization of process parameters through statistical 612 experimental designs. Process Biochem. 40, 1707-1714.

613 Ainsworth, P., Ibanoglu, S., Plunkett, A., Ibanoglu, E., Stojceska, V., 2007. Effect of brewers 614 spent grain addition and screw speed on the selected physical and nutritional properties of an 615 extruded snack. J. Food Eng. 81, 702-709.

616 Bartolomé, B., Santos, M., Jiménez, J.J., del Nozal, M.J., Gómez-Cordovés, C., 2002.

617 Pentoses and hydroxycinnamic acids in brewer's spent grain. J Cereal Sc. 36, 51-58.

618 Cacace, J.E., Mazza, G., 2003. Optimization of extraction of anthocyanins from black 619 currants with aqueous ethanol. J. Food Sc. 68, 240-248.

620 Carvalheiro, F., Esteves, M.P., Parajó, J.C., Pereira, H., Gírio, F.M., 2004. Production of 621 oligosaccharides by autohydrolysis of brewery's spent grain. Bioresource Technol. 91, 93622100

623 Charalampopoulos, D., Pandiella, S.S., Webb, C., 2002. Growth studies of potentially 624 probiotic lactic acid bacteria in cereal-based substrates. J. Appl. Microbiol. 92, 851-859.

625 Desjardins, M.-L., Roy, D., Toupin, C., 1990. Uncoupling of growth and acids production in 626 Bifidibacterium spp. J. Dairy Sc. 73, 1478-1484.

627 Dubois, M., Gilles, K.A., Hamilton, J.K., Rebers, P.A., Smith, F., 1956. Colorimetric method 628 for determination of sugars and related substances. Anal. Chem. 28, 350-356.

629 El-Shafey, E.I., Gameiro, M.L.F., Correia, P.F.M., De Carvalho, J.M.R., 2004. Dewatering of 630 brewer's spent grain using a membrane filter press: a pilot plant study. Separ. Sc. Technol. $63139,3237-61$.

632 Franco, D., Pinelo, M., Sineiro, J., \& Núñez, M.J., 2007. Processing of Rosa rubiginosa: 633 Extraction of oil and antioxidant substances. Bioresource Technol. 98, 3506-3512. 
634 Gupta, S., Cox, S., Abu-Ghannam, N., 2010. Process optimization for the development of a 635 functional beverage based on lactic acid fermentation of oats. Biochem. Eng. J. 52, 199-204. 636 Harbaum, B., Hubbermann, E.M., Zhu, Z., Schwarz, K., 2008. Impact of fermentation on 637 phenolic compounds in leaves of Pak Choi (Brassica campestris L. ssp. chinensis var. 638 communis) and Chinese Leaf Mustard (Brassica juncea Coss). J. Agric. Food Chem. 56, 148639157.

640 Heong, C.S., Kaur, B., Huda, N., Karim, A.A., Fazilah, A., 2011. Effect of fermentation on 641 the composition of Centella asiatica Teas. Am. J. Food Technol. 6, 581-593.

642 Jaiswal, A.K., Rajauria, G., Abu-Ghannam, N., Gupta, S., 2012. Effect of different solvents 643 on polyphenolic content, antioxidant capacity and antibacterial activity of Irish York 644 cabbage. J. Food Biochem. 36, 344-358.

645 Kedia, G., Vázquez, J.A., Pandiella, S.S., 2008. Fermentability of whole oat flour, PeriTec 646 flour and bran by Lactobacillus plantarum. J. Food Eng. 89, 246-249.

647 Kedia, G., Wang, R., Patel, H., Pandiella, S.S., 2007. Use of mixed cultures for the 648 fermentation of cereal-based substrates with potential probiotic properties. Process Biochem. $64942,65-70$.

650 Kun, S., Rezessy-Szabó, J.M., Nguyen, Q.D., Hoschke, A., 2008. Changes of microbial 651 population and some components in carrot juice during fermentation with selected 652 Bifidobacterium strains. Process Biochem. 43, 816-821.

653 Liu, S.C., Lin, J.T., Wang, C.K., Chen, H.Y., Yang, D.J., 2009. Antioxidant properties of 654 various solvent extracts from lychee (Litchi chinenesis Sonn.) flowers. Food Chem. 114, $655 \quad 577-581$.

656 Maaroufi, C., Melcion, J.P., de Monredon, F., Giboulot, B., Guibert, D., Le Guen, M.P., 657 2000. Fractionation of pea flour with pilot scale sieving. I. Physical and chemical 658 characteristics of pea seed fractions. Anim. Feed Sc. Technol. 85, 61-78. 
659 Mårtensson, O., Öste, R., Holst, O., 2002. The effect of yoghurt culture on the survival of 2 4

660

661 probiotic bacteria in oat-based, non-dairy products. Food Res. Int. 35, 775-84.

Mussatto, S.I., Fernandes, M., Dragone, G., Mancilha, I.M., Roberto, I.C., 2007. Brewer's spent grain as raw material for lactic acid production by Lactobacillus delbrueckii. Biotechnol. Lett. 29, 1973-1976.

Nazzaro, F., Fratianni, F., Sada, A., Orlando, P., 2008. Synbiotic potential of carrot juice supplemented with Lactobacillus spp. and inulin or fructooligosaccharides. J. Sc. Food Agric. $88,2271-2276$.

Oyarekua, M.A., 2010. Sensory evaluation, nutritional quality and antinutritional factors of traditionally co-fermented cereals/cowpea mixtures as infant complementary food. Agric. Biol. J. North Am. 1, 950-956.

Öztürk, S., Özboy, O., Cavidoğlu, İ., Köksel, H., 2002. Effects of Brewers’ spent grain on the quality and dietary fiber content of cookies. J. Inst. Brew. 108, 23-27.

Patel, H.M., Pandiella, S.S., Wang, R.H., Webb, C., 2004. Influence of malt, wheat and barley extracts on the bile tolerance of selected strains of lactobacilli. Food Microbiol. 21, $83-89$.

Pinelo, M., Rubilar, M., Jerez, M., Sineiro, J., Nunez, M.J., 2005. Effect of solvent, temperature, and solvent-to-solid ratio on the total phenolic content and antiradical activity of extracts from different components of grape pomace. J. Agric. Food Chem. 53, 2111-2117.

Qi, B., Yao, R., 2007. L-lactic acid production from Lactobacillus casei by solid state fermentation using rice straw. Bioresources 2, 419-429.

Qu, W., Pan, Z., Ma, H., 2010. Extraction modeling and activities of antioxidants from pomegranate marc. J. Food Eng. 99, 16-23. 
Rozada, R., Vázquez, J.A., Charalampopoulos, D., Thomas, K., Pandiella, S.S., 2009. Effect

of storage temperature and media composition on the survivability of Bifidobacterium breve NCIMB 702257 in a malt hydrolisate. Int. J. Food Microbiol. 133, 14-21.

685 Taga, M.S., Miller, E.E., Pratt, D.E., 1984. Chia seeds as a source of natural lipid 686 antioxidants. J. Am. Oil Chem. Soc. 61, 928-31.

687 Tolonen, M., Rajaniemi, S., Pihlava, J.M., Johansson, T., Saris, P.E.J., Ryhanen, E.L., 2004. 688 Formation of nisin, plant-derived biomolecules and antimicrobial activity in starter culture 689 fermentations of sauerkraut. Food Microbiol. 21, 167-179.

690 Valverde, P., 1994. Barley spent grain and its future. Cerveza y Malta 122, 7-26.

691 Xiao, J.H., Chen, D.X., Wan, W.H., Hu, X.J., Qi, Y., Liang, Z.Q., 2006. Enhanced 692 simultaneous production of mycelia and intracellular polysaccharide in submerged cultivation 693 of Cordyceps jiangxiensis using desirability functions. Process Biochem. 41, 1887-1893.

694 Yoon, K.Y., Woodams, E.E., Hang, Y.D., 2006. Production of probiotic cabbage juice by 695 lactic acid bacteria. Bioresource Technol. 97, 1427-30. 

6

Figure 1: Contour plot showing the effect of experimental factors on the growth of (a) $L$. plantarum, (b) lactic acid, (c) TPC, (d) TFC, (e) FRAP and (f) DPPH

Figure 2: Multi response optimization showing desirability ramp for numerical optimization Figure 3: A comparative HPLC-DAD chromatogram of $\mathrm{BSG}$ broth for tentative identification of phenolic groups at $280 \mathrm{~nm}$ after various processing treatments (3a) SA broth; (3b) DA broth; (3c) fermented broth. Peaks marked: 1-hydroxybenzoic acid derivatives; 2hydroxycinnamic acid derivatives

Figure 4: Effect of storage time on the $\log \mathrm{cfu} / \mathrm{ml}(\diamond), \mathrm{pH}(\Delta)$ and lactic acid $(\mathrm{g} / \mathrm{l})(\square)$ of the BSG based liquid product

Figure 5: Growth kinetics of L. plantarum in a 7 L bioflo bioreactor $(\diamond: \log$ cfu/ml; $\square$ : Lactic $\operatorname{acid}(\mathrm{g} / \mathrm{l}) ; \Delta:$ total sugar $(\mathrm{g} / \mathrm{l}))$ 
712 Table 1: Level and code of independent variables used for Box-Behnken experimental design 1 $\begin{array}{ll}2 & 713\end{array}$

\begin{tabular}{lcccc}
\hline Independent variables & Coded symbols & \multicolumn{3}{l}{ Levels } \\
& & & & \\
& & & & \\
& & & & \\
& $\mathrm{X}_{1}$ & 8 & 16 & 24 \\
\hline Fermentation time (h) & & & & \\
\hline Solid liquid ratio & $\mathrm{X}_{2}$ & 0.05 & 0.15 & 0.25 \\
\cline { 2 - 5 } Agitation $(\mathrm{rpm})$ & $\mathrm{X}_{3}$ & 0 & 100 & 200 \\
\cline { 2 - 5 } Particle size $(\mu \mathrm{m})$ & $\mathrm{X}_{4}$ & 350 & 525 & 700
\end{tabular}




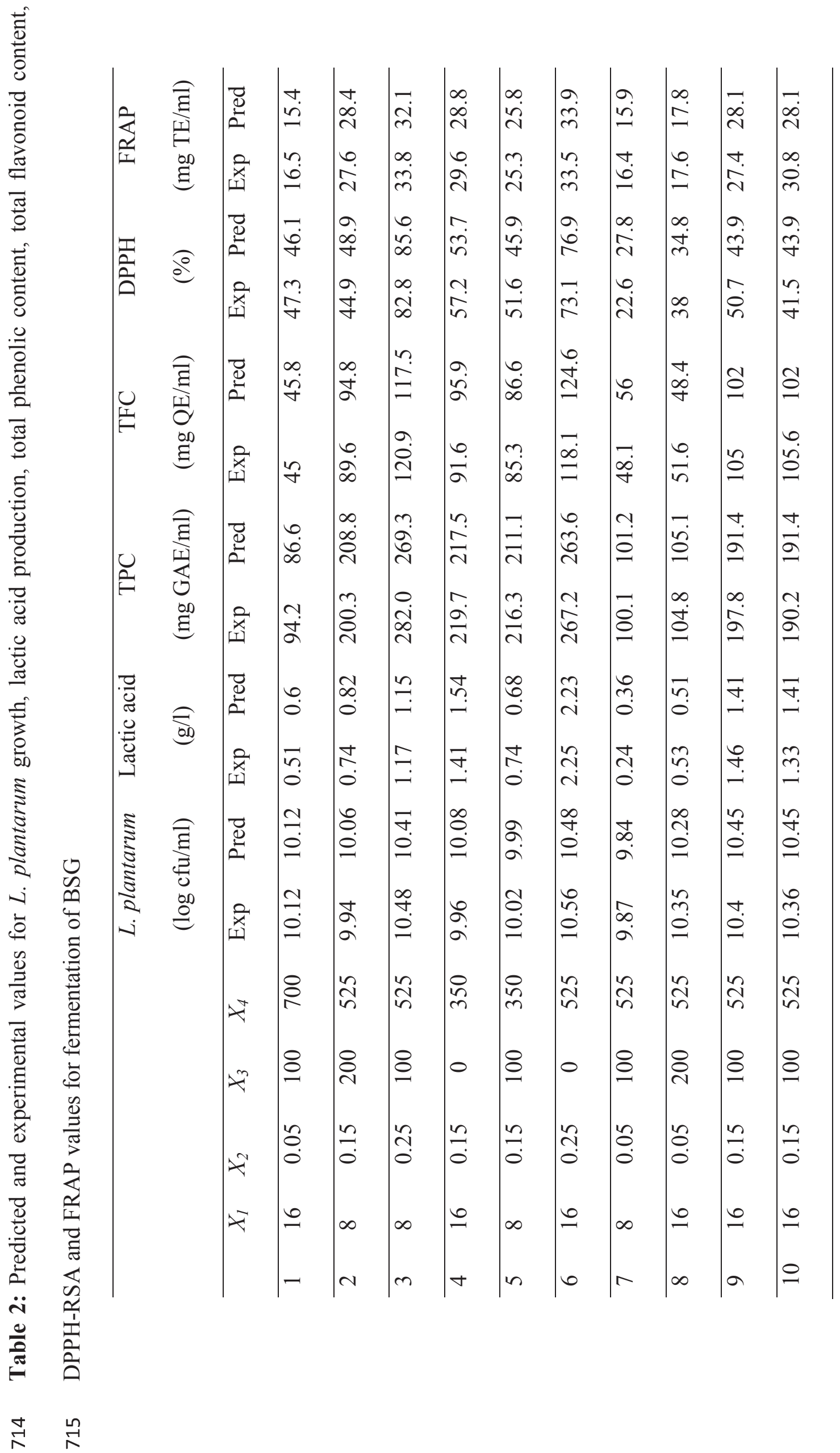




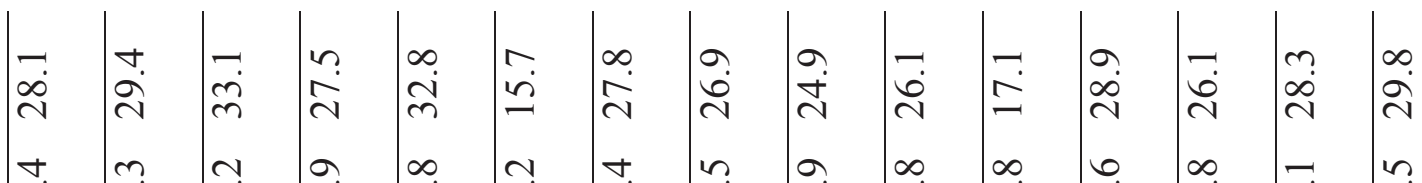

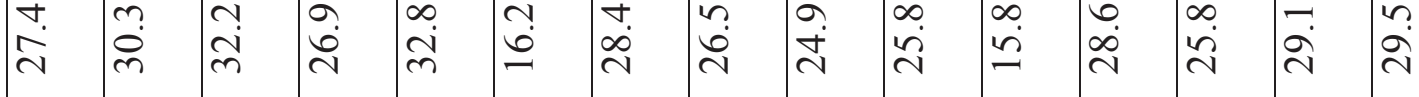

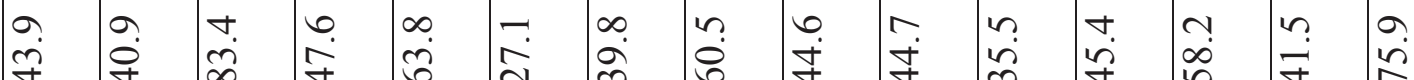

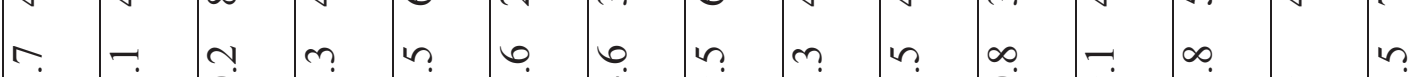

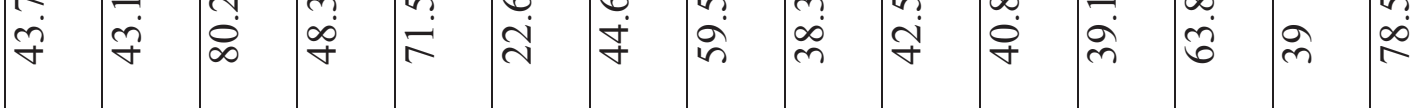

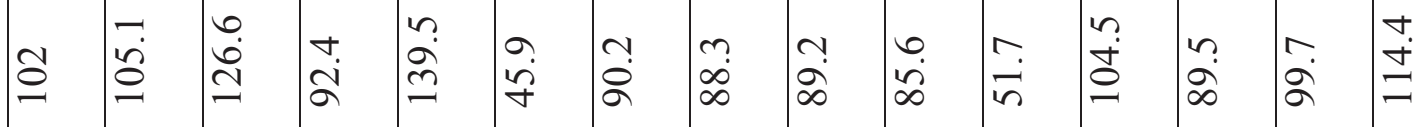

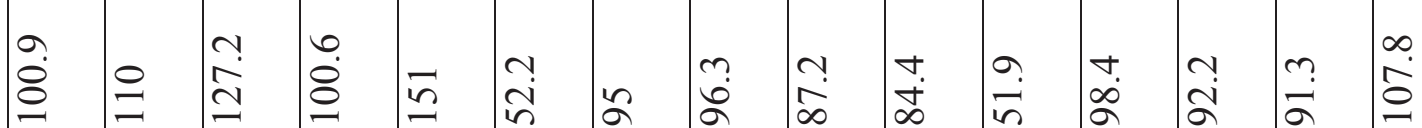

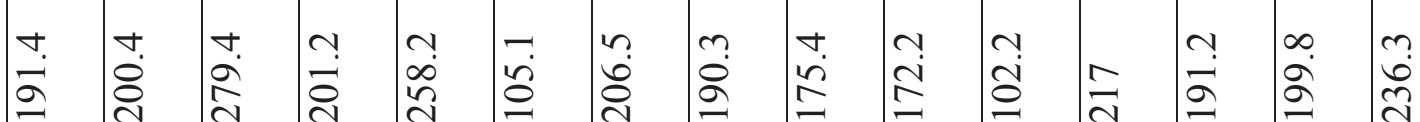

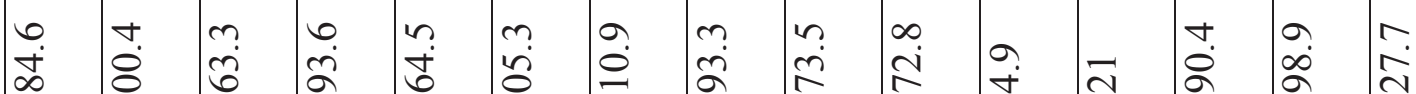

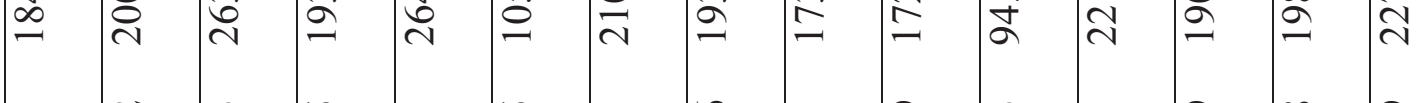

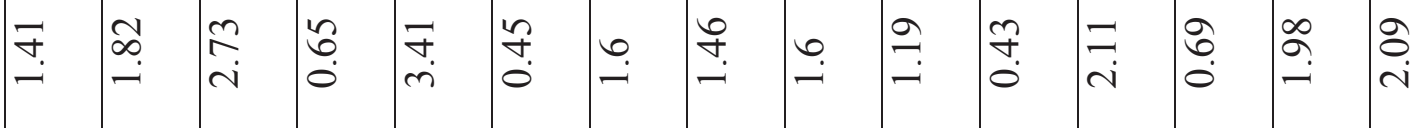

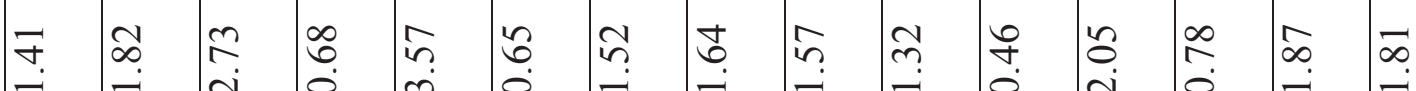

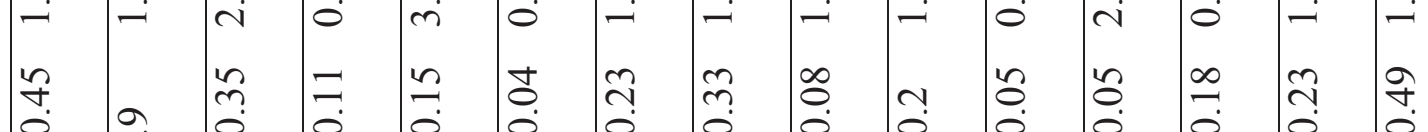

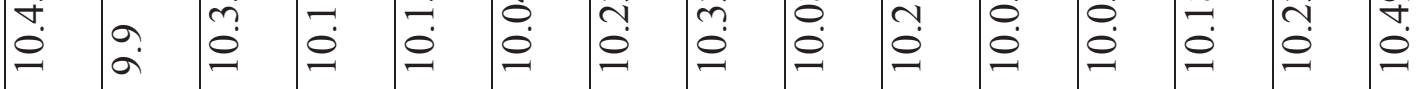

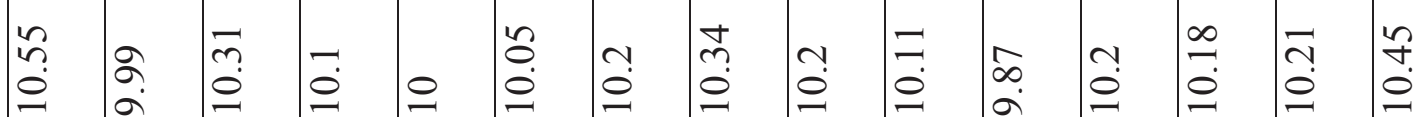
n n

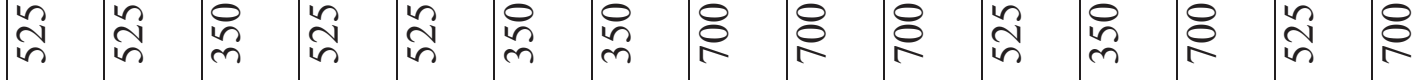
\&

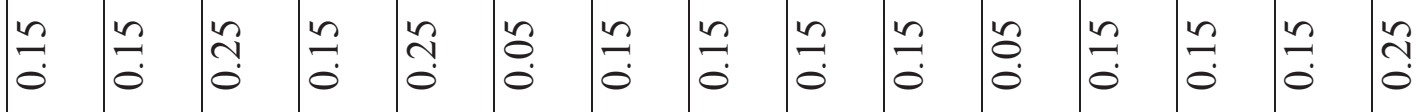

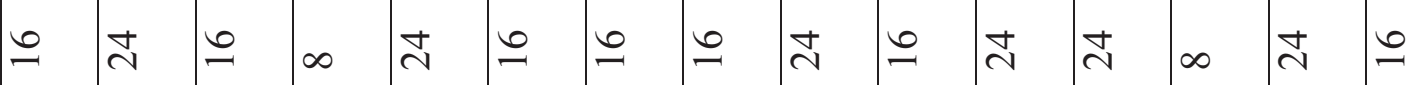

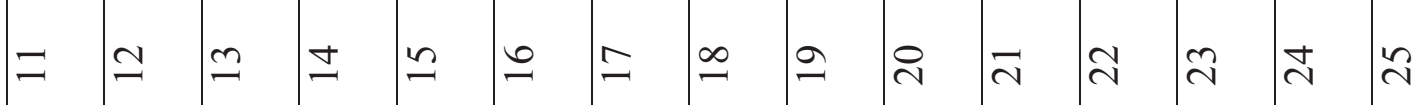




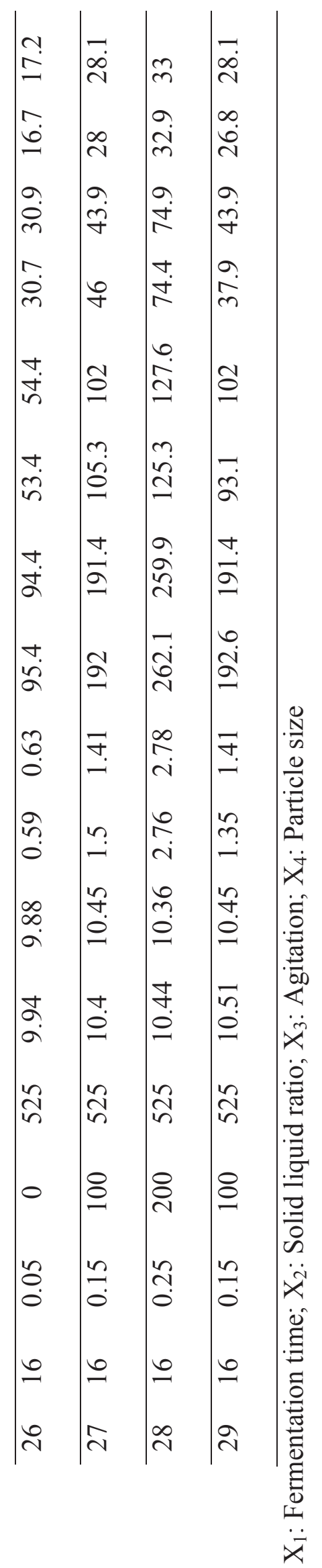

$\stackrel{n}{\stackrel{n}{n}}$

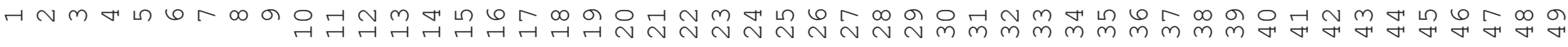




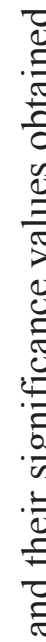

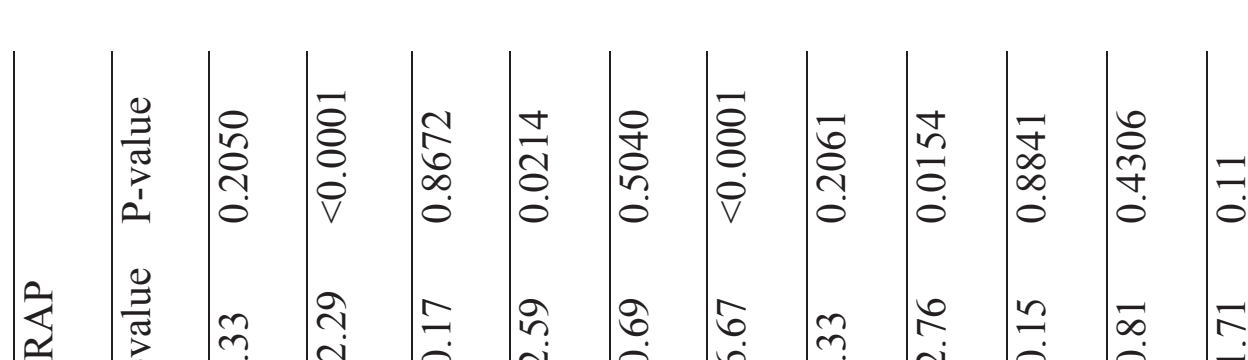

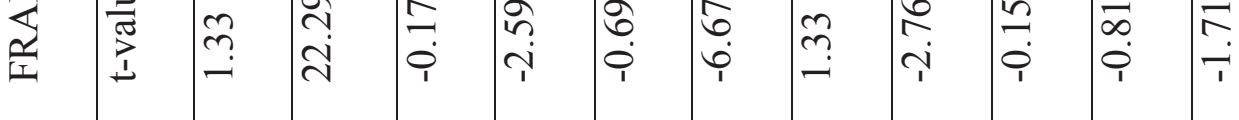

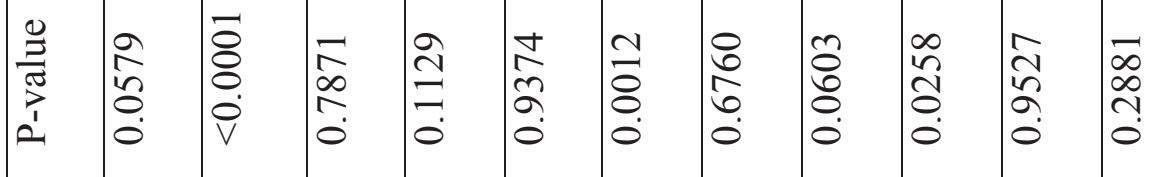

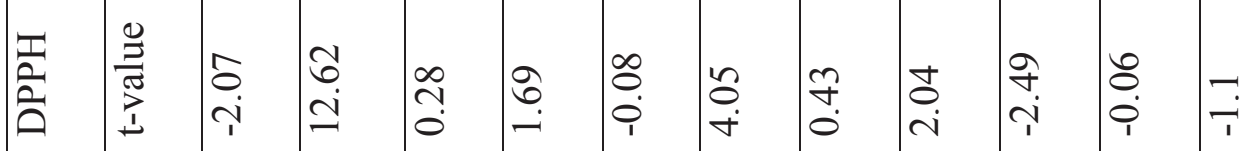

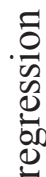
공 :

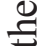

:

훙

:

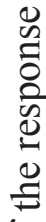

잉

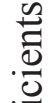

莬

i

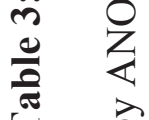

$\stackrel{\infty}{\stackrel{9}{1}}$

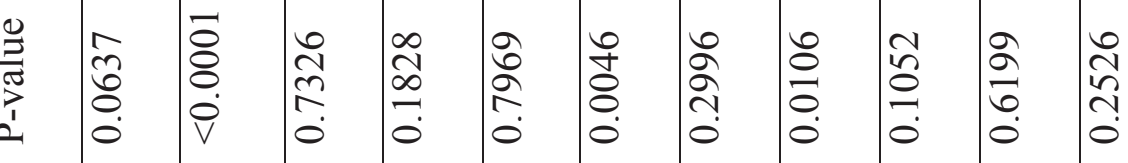

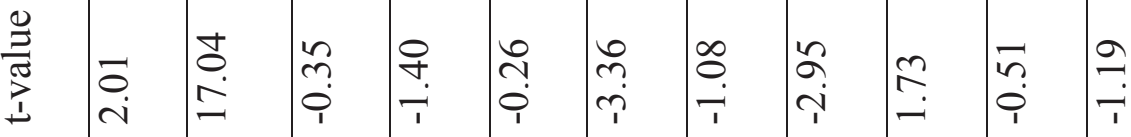

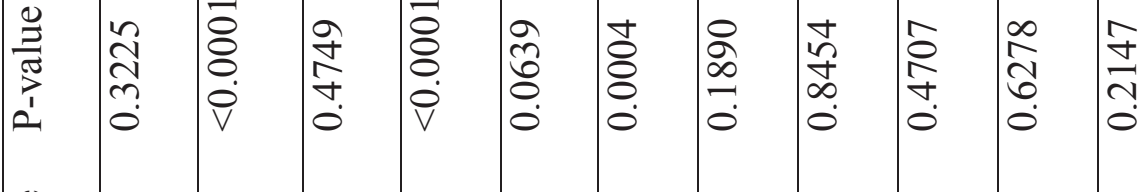

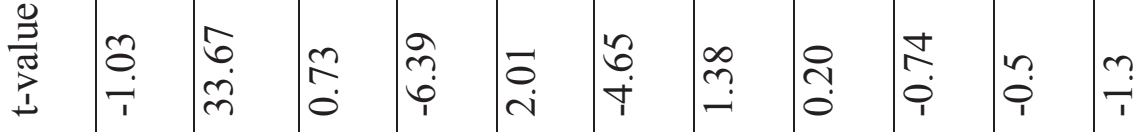

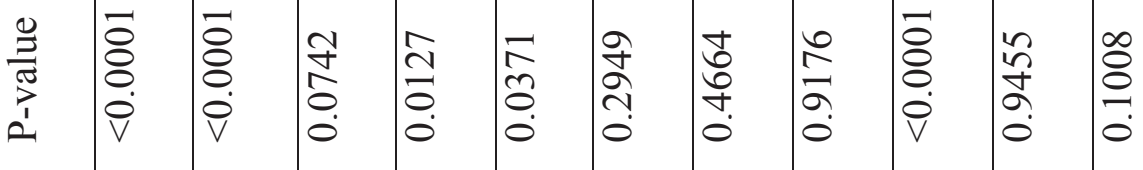

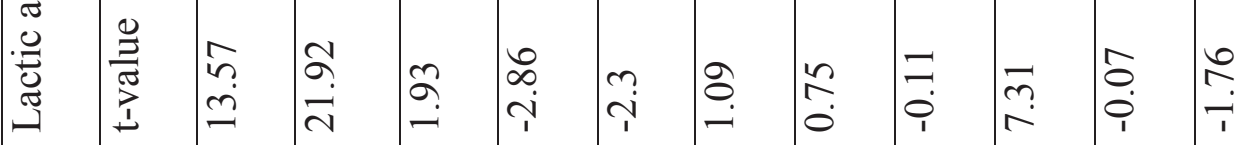

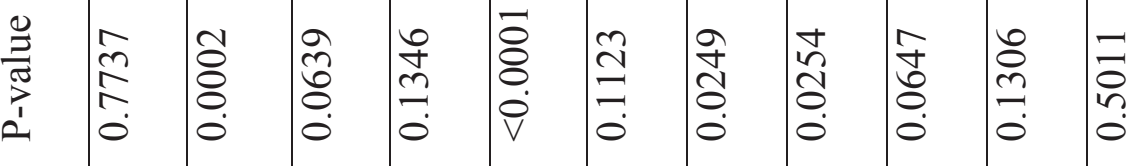

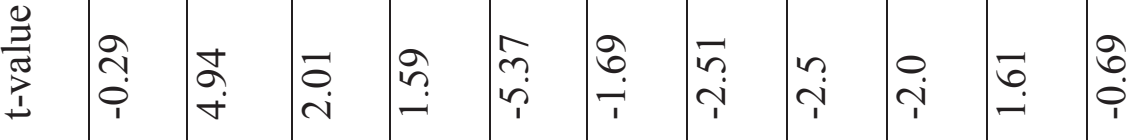

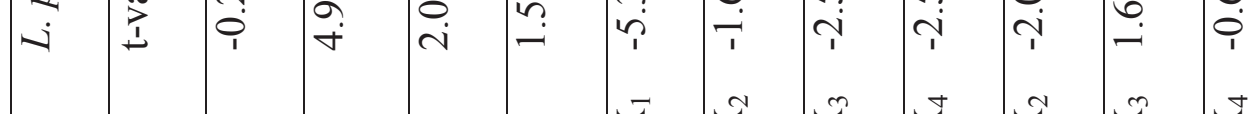

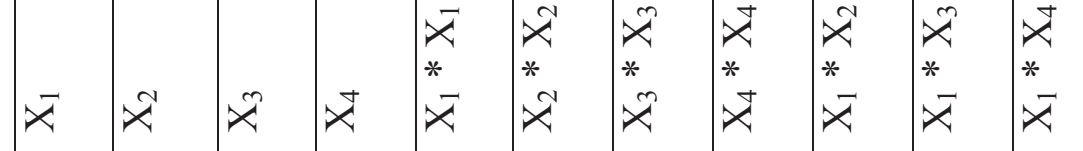

๙ 


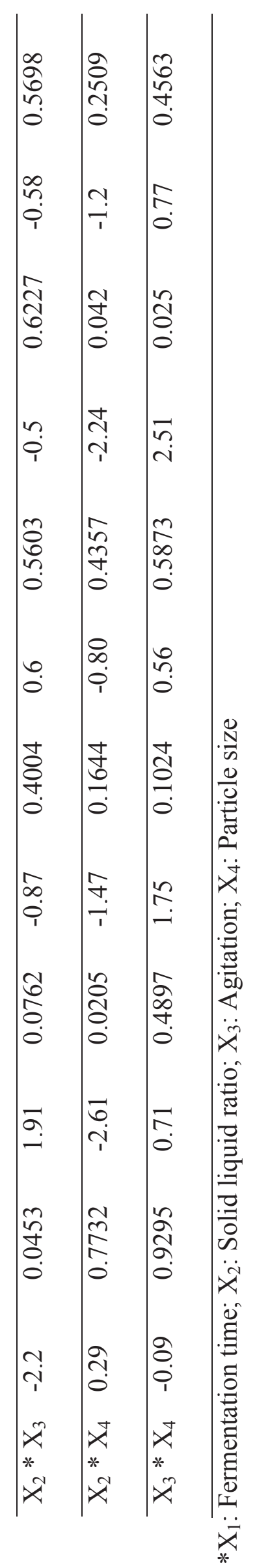

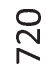

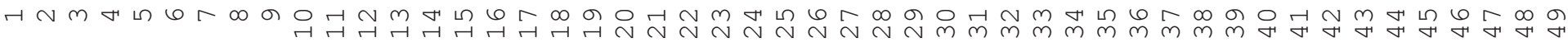


721 Table 4: Hydroxybenzoic acids (HBA) and hydroxycinnamic acids (HCA) contents of broth 1 722 at different stages of BSG fermentation

\begin{tabular}{lccc}
\hline & HBA $(\mathrm{GAE} / \mathrm{ml})$ & HCA $(\mathrm{CAE} / \mathrm{ml})$ & Total \\
\hline SA broth & $50.9 \pm 6.4$ & $10.7 \pm 0.8$ & 61.68 \\
\cline { 2 - 4 } DA broth & $61.9 \pm 0.13$ & $8.13 \pm 0.74$ & 70.4 \\
\cline { 2 - 4 } Fermented broth & $53.7 \pm 0.2$ & $9.8 \pm 0.22$ & 63.49 \\
\cline { 2 - 4 } Shelf life (day 15) & $36.1 \pm 0.04$ & $7.65 \pm 0.2$ & 43.76 \\
\cline { 2 - 3 } Shelf life (day 30) & $35.7 \pm 3.2$ & $8.1 \pm 0.06$ & 43.8
\end{tabular}




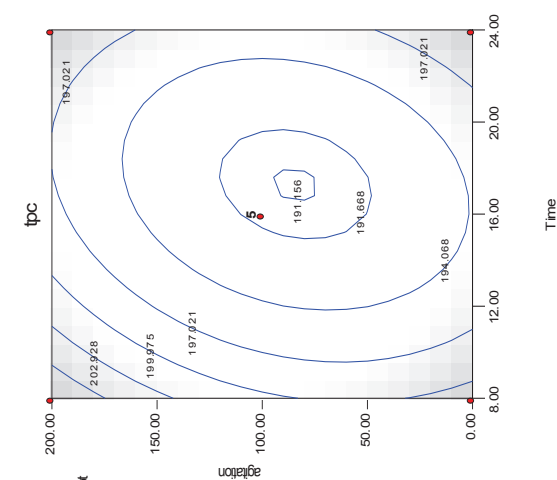

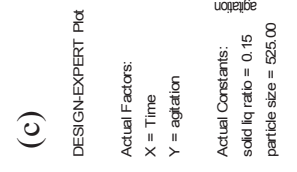
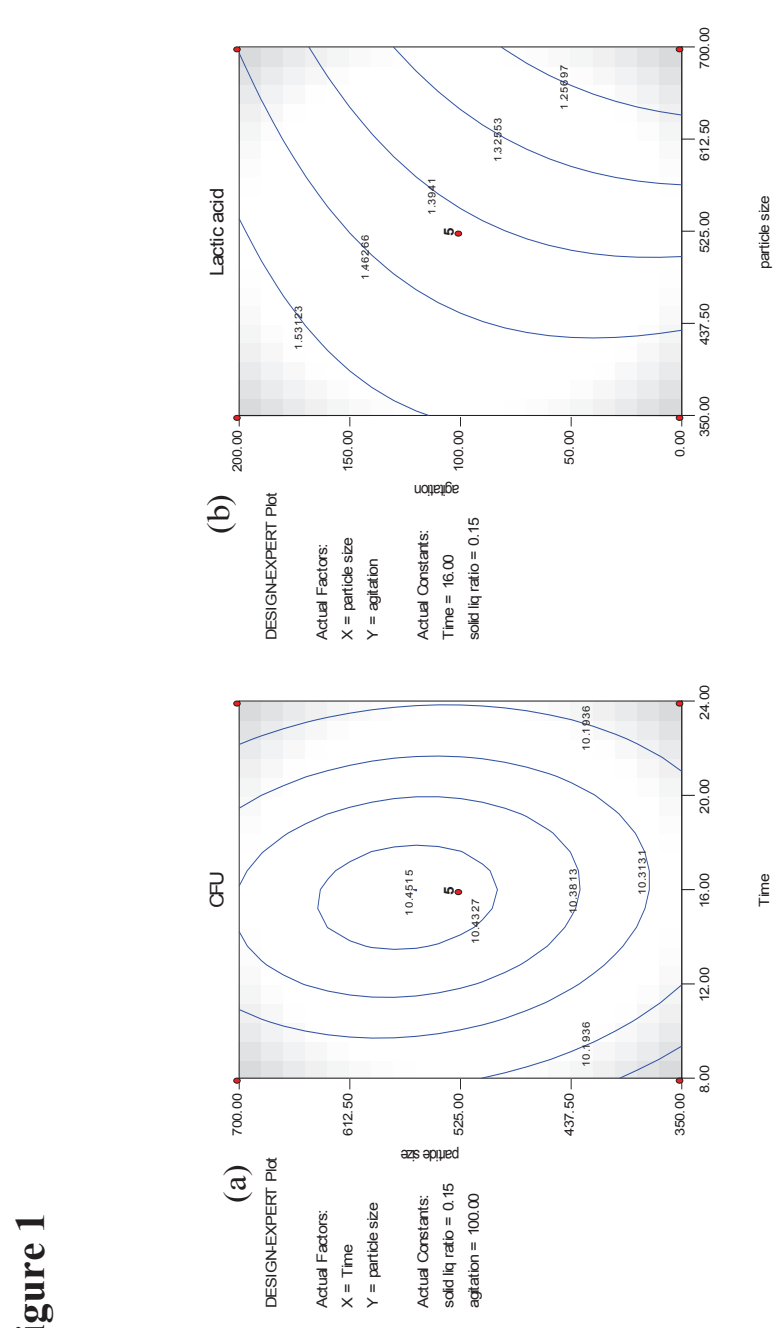

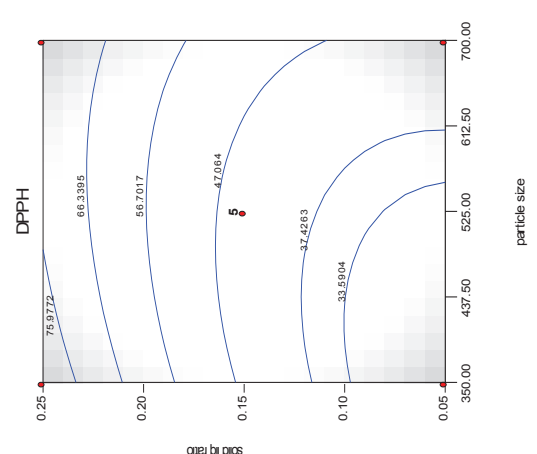

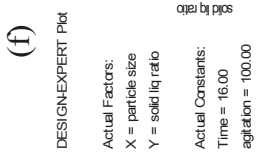

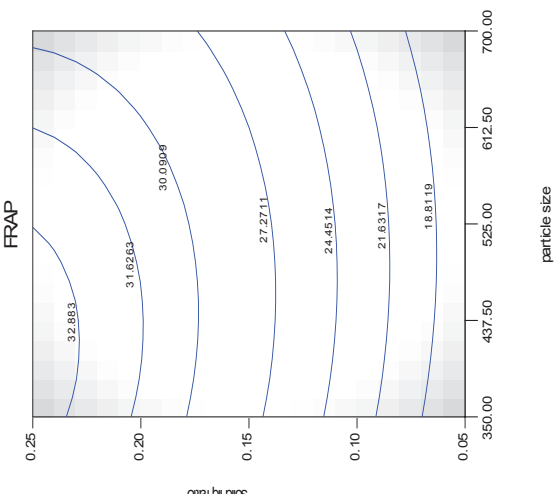

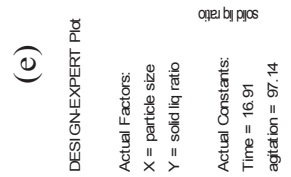

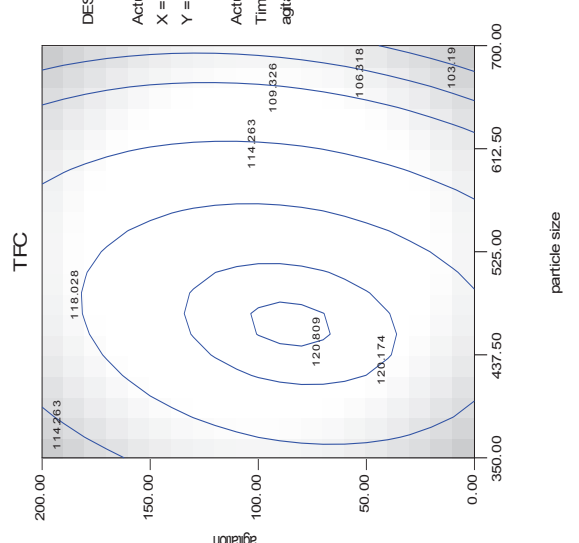

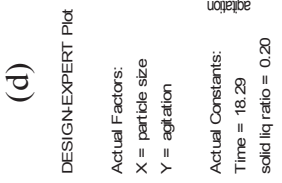

$\stackrel{\sim}{N}$ 
Figure 2

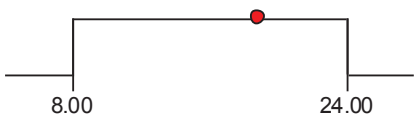

Time $=18.91$

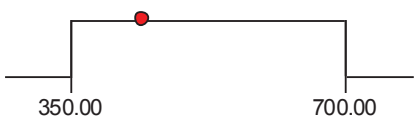

particle size $=440.64$

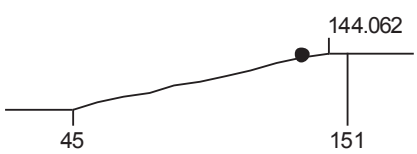

$\mathrm{TFC}=134.872$

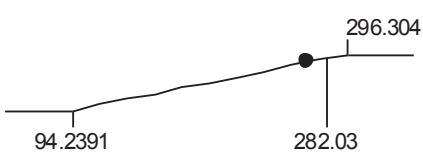

tpc $=268.579$

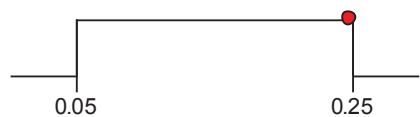

solid liq ratio $=0.25$

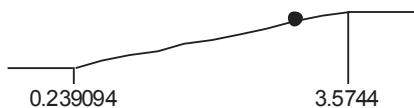

actic acid $=2.95172$

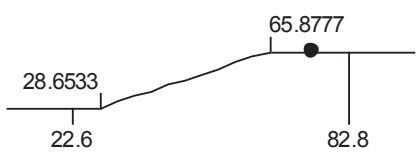

$\mathrm{DPPH}=75.1374$

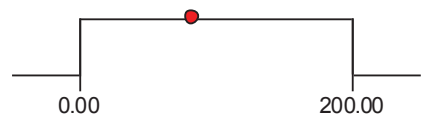

agitation $=84.34$

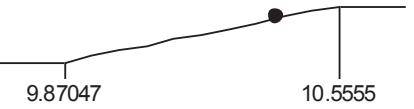

$\mathrm{CFU}=10.4017$

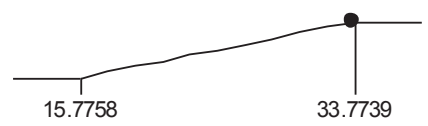

FRAP $=33.7179$

Desirability: 0.882 
Figure 3

(a)

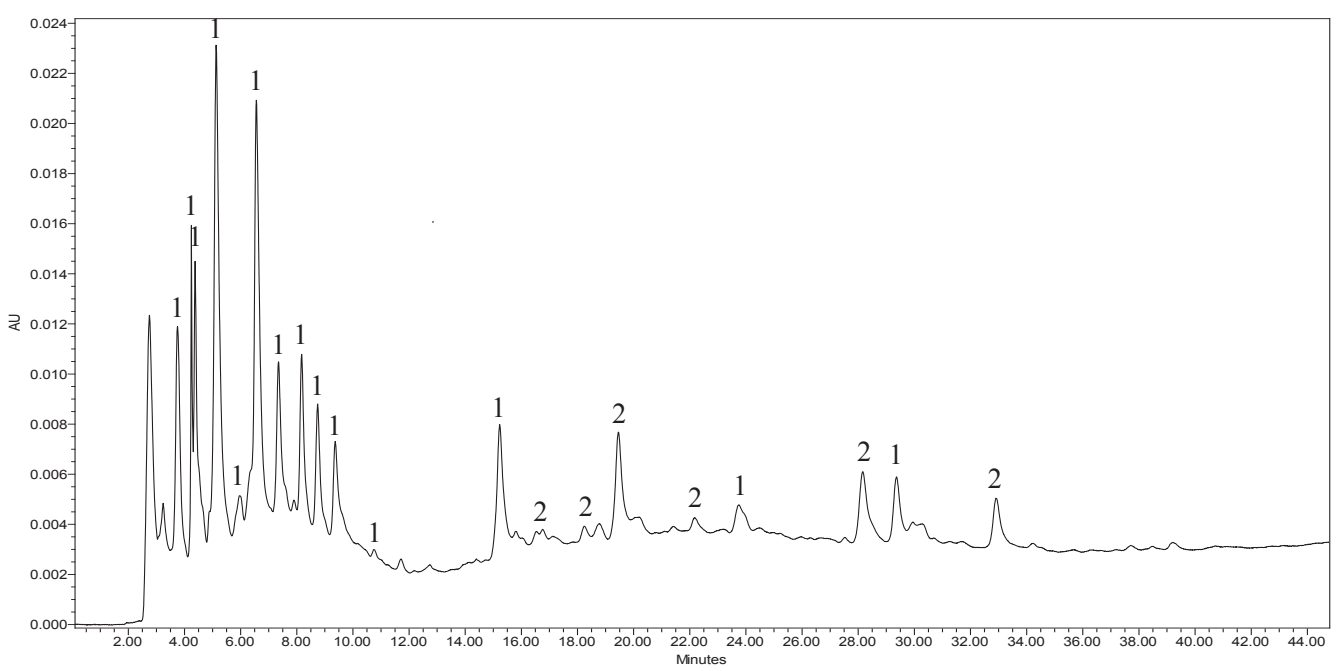

(b)

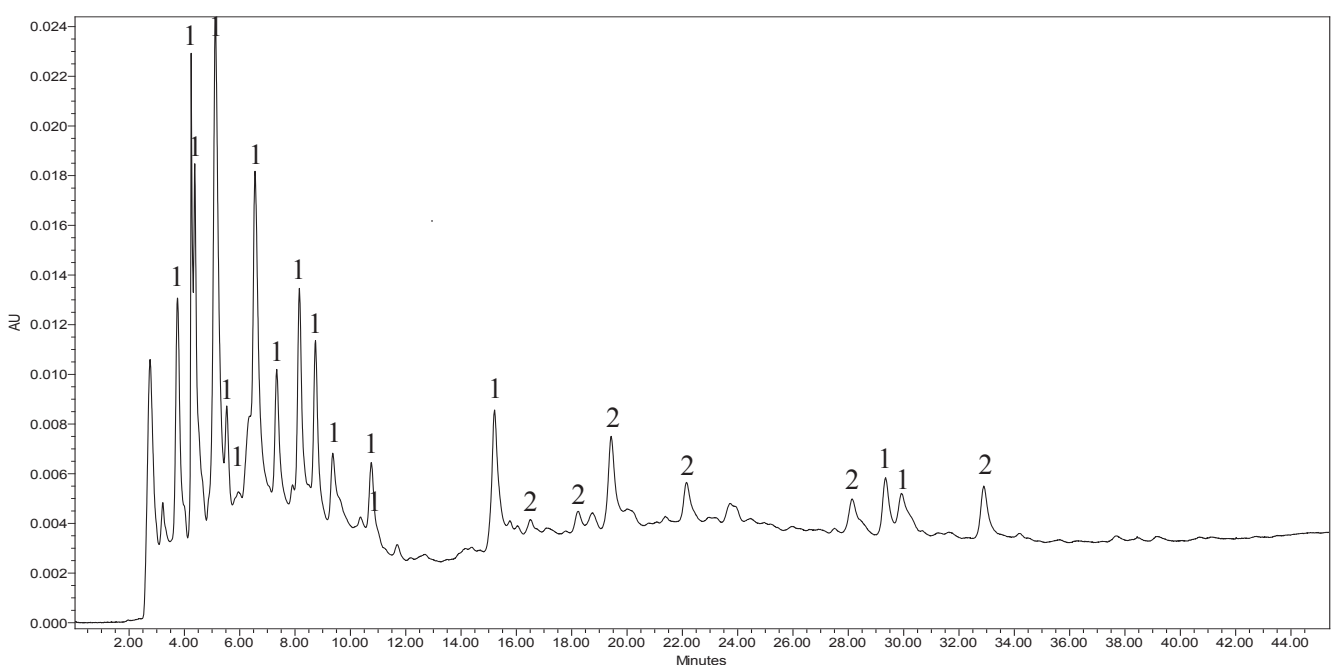

(c)

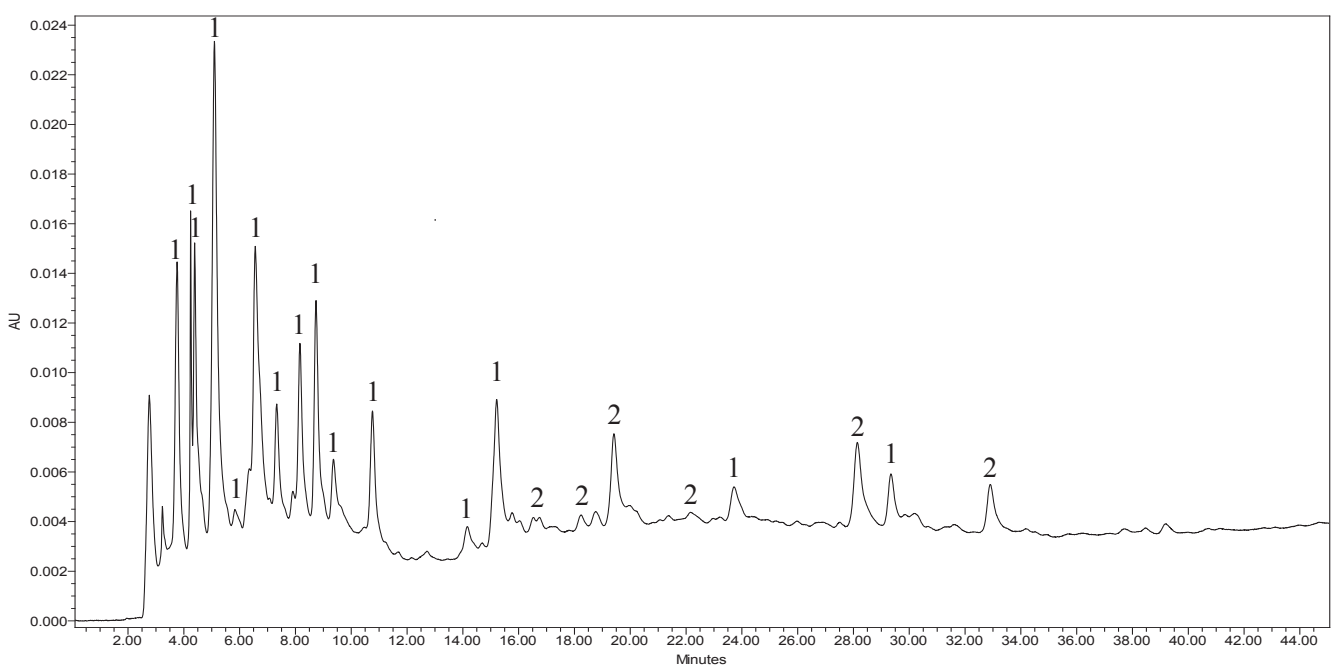


$732 \quad$ Figure 4

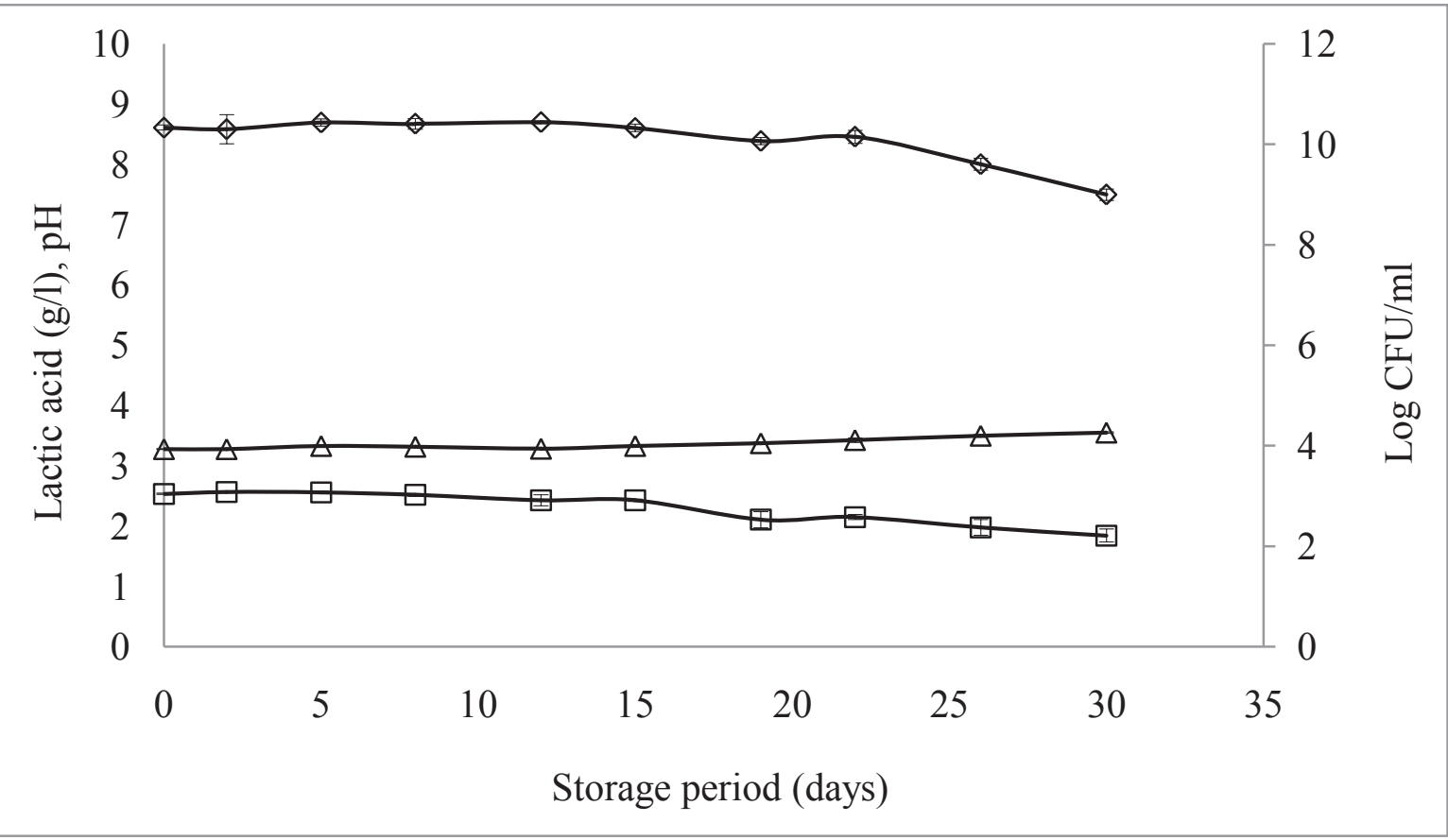


$736 \quad$ Figure 5

1

2

3

4

5

9

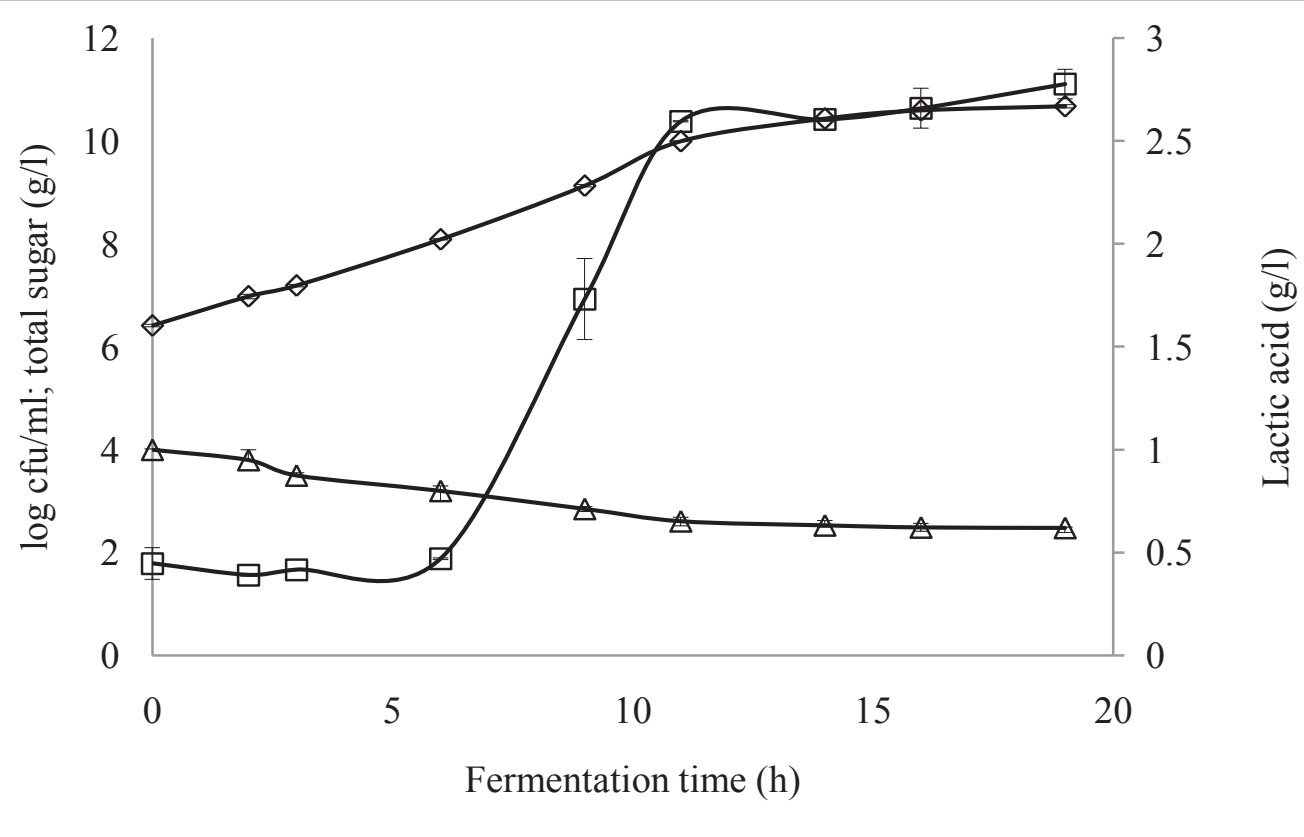

